This document is the accepted manuscript version of the following article:

Haag, F., Zürcher, S., \& Lienert, J. (2019). Enhancing the elicitation of

diverse decision objectives for public planning. European Journal of operational

Research, 279(3), 912-928. https://doi.org/10.1016/j.ejor.2019.06.002

This manuscript version is made available under the CC-BY-NC-ND 4.0

1icense http://creativecommons.org/1icenses/by-nc-nd/4.0/

\title{
Enhancing the elicitation of diverse decision objectives for public planning
}

Fridolin Haaga,b, , Sara Zürchera, Judit Lienerta

\author{
a Eawag: Swiss Federal Institute of Aquatic Science and Technology, Überlandstrasse 133, 8600 Dübendorf, \\ Switzerland \\ b ETH Zürich, Institute of Biogeochemistry and Pollutant Dynamics, Universitätstrasse 16, 8092 Zürich, \\ Switzerland \\ *Corresponding author: fridolin.haag@eawag.ch; co-authors: judit.lienert@eawag.ch, \\ sara.zuercher@eawag.ch
}

European Journal of Operational Research, 279: 912-928.

https://doi.org/10.1016/i.ejor.2019.06.002

\begin{abstract}
Identifying objectives is essential for decision making, but individuals have difficulties stating their important objectives. In public and environmental decisions, the diverse views of stakeholders should be included, but eliciting a broad set of objectives is challenging. We (1) study the effectiveness of individual brainstorming for eliciting objectives in a real-world setting; (2) test three interventions to support individuals in generating objectives; (3) investigate which and how many stakeholders are necessary to generate a comprehensive set of objectives; and (4) develop a feasible elicitation procedure for practice. In an experimental test, 71 stakeholders participated in five decisions about regional wastewater infrastructure planning in Switzerland. Three interventions were tested with an online survey procedure: (i) providing category cues, (ii) a perspective-taking task, and (iii) providing a predefined master list of objectives. In simple brainstorming, participants stated few objectives $(M=3.3)$ associated with 2.9 different categories on average. Participants consistently missed objectives they later considered important. Providing a master list was the only intervention that substantially increased the number and breadth of objectives ( $M=12$ objectives in $M=5.3$ categories). With the help of our survey, participants generated between 30 and 38 distinct objectives for each decision case. Between five and nine participants were sufficient to generate these; more participants did not contribute new objectives. Most decision makers need help generating their objectives; combining simple brainstorming with a master list is a straightforward improvement that does not require a facilitator. An online process is promising for involving a large group of stakeholders.
\end{abstract}

\section{Keywords:}

Behavioural OR; Decision Analysis; Online elicitation; Urban water management; Environmental decision 


\section{Introduction}

Knowledge about objectives is decisive for any analytical decision-making effort (e.g., Keeney 1992). In a rational decision, the selection of an alternative is based on its achievement of objectives. Thus, in procedures such as multi-criteria decision analysis (MCDA), identifying objectives at the beginning is key (Keeney 1992; Gregory et al. 2012; Reichert et al. 2015). As the objectives define the content of the evaluation, analysis, and discussion of alternatives, different sets of objectives can lead to different decisions (Brownlow and Watson 1987). The omission of objectives, perhaps due to an oversimplified problem representation, can bias the analysis (Payne et al. 1999; Montibeller and von Winterfeldt 2015). Therefore, the set of objectives should be generated carefully. However, in actual decisions, objectives are often not identified at all, or only cursorily (e.g. Gregory et al. 2012).

For public and environmental decisions, the identification of objectives is both particularly relevant and particularly difficult. The normative demand is that these decisions serve the public interest. Objectives can be an appropriate level at which to operationalize this concept and formulate an integrated perspective on these decisions. Often, a few individuals take these decisions on behalf of a much larger group of stakeholders. However, how we can support these representatives in generating a set of objectives that addresses a wide range of concerns is an open question. It is also unclear how the public can be directly involved in this process.

At first glance, the task of identifying objectives appears trivial: we just ask the decision makers to list what they want. However, the process of eliciting and structuring objectives is often considered "more of an art than a science" (Keeney 1988). Bond et al. $(2008,2010)$ have found that individual decision makers are unable to fully articulate their objectives and without additional support neglect objectives they actually consider important. The creativity of individuals in objective generation may be either facilitated or hindered by group, organizational, and institutional factors (cf. Ford 1996). The challenges to generating objectives are reviewed in section 3 .

For group processes, effective methods exist to aid the generation of objectives. Problem structuring methods (Mingers and Rosenhead 2004; Marttunen et al. 2017) - such as cognitive mapping (Montibeller and Belton 2006) and soft systems methodology (Neves et al. 2009) - often support the identification of objectives as part of the process. This can even lead to overly large sets of objectives that need be reduced to a fundamentally relevant set for meaningful analysis (Marttunen et al. 2019). In practice, time and resource constraints often hinder a thorough application of problem structuring processes. Moreover, the need for direct interaction between participants limits the number of people that can productively participate; but restricting access raises questions about procedural justice, especially for public decisions (cf. Fiorino 1990). In addition, an experienced facilitator is required but is not always available. 
We aim at involving a large number of individuals (e.g. the public) in the objective generation process. Therefore, we investigated how individuals can be supported to generate objectives without a facilitator. We tested three interventions that might be helpful (section 5.2 ). Because public and environmental planning necessarily involves a wide range of considerations (Keeney 1988), we aimed at increasing both the number and the breadth of objectives. Public elicitation requires a scalable solution. To meet this need, we developed an online survey tool. The research is based on five wastewater infrastructure planning cases.

The next section explains the public planning context that motivates this study. Section 3 reviews the challenges of generating objectives. Section 4 presents the research questions. Section 5 details the approach to objective generation and the methods for analyzing the experiment. Section 6 presents the results of the experiment, and section 7 discusses them. Finally, section 8 summarizes the main contributions and offers conclusions.

\section{Objectives in public planning: the case of wastewater}

Infrastructure for wastewater disposal provides fundamental services to society and the economy. Wastewater has negative impacts on environment and health, which the treatment infrastructure reduces. In Europe, wastewater infrastructure is usually characterized by long lifespans of capital-intense assets and an interconnectedness of system components (Markard 2011). The responsibility for operations and planning often lies with public organizations. The strategic decisions are complex, require trade-offs between several objectives, and affect many people. While we focus on the water sector, similar characteristics are found in other areas of public planning, such as energy and transport.

These planning challenges have been approached by different institutional logics. We can classify these into three ideal types: (1) a historically dominant hydraulic logic, (2) a water-market logic with a focus on economic efficiency, and (3) a water-sensitive logic with a focus on sustainability (Fuenfschilling and Truffer 2014). These logics differ in their predominant approaches to decision making. The strategic objectives differ, as do the processes of determining decision objectives. Although the logics are ideal types and the actual practices are more nuanced, they are useful for understanding potential barriers to the generation of objectives (see section 3.3 ).

Hydraulic logic predominated throughout the $20^{\text {th }}$ century and in many places still does today. Here, planning is shared between state and professional actors. The state is responsible for funding and regulation, while engineers attempt to solve the issues by building technical solutions (Fuenfschilling and Truffer 2014). State action is oriented towards the public good, which is codified into a few objectives (health protection, flood protection, environmental protection, low costs). Objectives are usually expressed through regulatory constraints. Engineering tries to find a feasible solution within these constraints, and compliance is a key driver for planning (Brown et al. 2009). Other objectives, perspectives, and stakeholders are only 
considered in an ad hoc fashion, depending on the decision makers. Only if regulations exist or come into play does regular consideration occur. For instance, Switzerland recently established regulations on micropollutant removal (Stamm et al. 2015) and phosphorous recovery from wastewater. Thus, micropollutant removal and phosphorous recovery became practically relevant decision objectives.

This predominant logic has been challenged by a water-market logic whose central values are economic efficiency and rationalization (Fuenfschilling and Truffer 2014). The decision-making processes are still handled by experts. Decisions are supported by cost-benefit analysis and supply-demand calculations. A central aim is full cost recovery from end-users. In practice, the regulatory power remains with the state; therefore, objectives given by regulations are still considered.

Water-sensitive logic is relevant for a transition towards more sustainability in the wastewater sector. Since neither a hydraulic nor a market logic seem capable of coping with all the current challenges, interest has grown in more integrated and holistic approaches to wastewater management (e.g., Brown et al. 2009; Larsen et al. 2016). This is facilitated by planning and decision-making processes that can cope with the increased complexity of stakeholders' interests, objectives, and technical alternatives (e.g., Lai et al. 2008; Lienert et al. 2015; Scholten et al. 2015).

Focusing on sustainability increases the diversity of decision objectives more radically. The functions of wastewater infrastructure broaden into multi-benefit infrastructure, for instance by using wastewater as a resource (Larsen et al. 2016; Harris-Lovett et al. 2018). Consequently, a number of multi-criteria assessments and life-cycle analyses have been developed to include a more comprehensive set of objectives in decision making (see Balkema et al. 2002; Lai et al. 2008; Spiller 2016 for reviews). A structuring of objectives for the Swiss water and wastewater sector has been conducted by Lienert et al. (2015). Concurrently, with a sustainability perspective the active role of stakeholders and the public is growing in importance (Meadowcroft 2004; Brown and Farrelly 2009).

Whichever logic is used for decision making, all decision processes are facilitated by the identification of relevant objectives. This seems especially important in sectors such as wastewater, where traditionally few objectives are considered and these are imposed by regulations. Evaluating multi-benefit infrastructures and intensifying public involvement requires new methods to broaden the range of issues and to elicit the values and objectives of diverse stakeholders. The methods developed and tested in this study are a step towards addressing these challenges. 


\section{Challenges when generating objectives}

\subsection{Individual level}

Individuals fail to generate a considerable proportion of the objectives they personally consider relevant when using brainstorming unaided, as was shown in two seminal studies (Bond et al. 2008, 2010). While we are not aware of other studies investigating this specific process, we can derive additional hints from studies on ideation, creativity, and cognition. We propose four explanatory dimensions for incomplete objective generation by individuals. (1) Unfamiliarity with the concept of objectives, (2) cognitive difficulty, (3) lack of motivation, and (4) contextual factors and institutional limits to thinking more broadly and deeply. Empirically, these dimensions are difficult to separate, because they interact. Each of them is discussed briefly in the following.

(1) Often, people are not used to thinking in terms of objectives, but in what Keeney (1992) calls "alternative-focused thinking". Here, alternatives are at the center of decision making, and objectives are only a means to compare alternatives. This can have many disadvantages compared to "value-focused thinking" (Keeney 1992).

(2) While theories on cognitive processes are much debated, we may differentiate between two pathways for the mental generation of objectives: recall of previously learned items, and ideation, the production of new ideas. Concerning recall, one important factor is the categorical clustering of ideas (see Bond et al. 2010). The basic idea is that concepts are stored in and retrieved from memory in a categorized way (Bousfield 1953; Gruenewald and Lockhead 1980). This implies a cognitive cost in crossing category boundaries. Thus, the availability (Tversky and Kahneman 1973) of concepts in other categories is lower. Ideation is more complex than recall, as it requires combining knowledge, forming new associations, and applying knowledge to a new domain, which can fail (Nijstad and Stroebe 2006). A third way of finding objectives is the recognition of an objective as relevant when it is presented. The recognition of items is often experienced as easier than either recall or ideation, which might be due to exposure effects (cf. Alter and Oppenheimer 2009).

(3) Motivation is an important component of idea creation (Paulus and Brown 2007). Generation of objectives requires mental effort (cf. Kirschner and Kirschner 2012). Hence, motivation is needed to complete the task despite this effort. Conversely, a lack of motivation due to intrinsic or extrinsic factors may lead to lower willingness to invest in objective generation (Bond et al. 2010).

(4) The popular expression "thinking outside the box" illustrates the phenomenon that our thinking is often limited by a "box": a complex interplay of personal and contextual factors. As argued in section 0, institutional logics can become such boxes, as they are internally selfconsistent systems of thinking. This may lead to an incomplete mental model of a problem, a myopic problem representation (Payne et al. 1999). This bias can also affect the breadth and diversity in the generation of objectives (Montibeller and von Winterfeldt 2015). A key to 
overcoming these limitations might lie in stimulating creativity (see Ford 1996; Anderson et al. 2014).

\subsection{Group level}

In many practical cases of decision support, decision objectives are generated in facilitated group workshops. Group elicitation with a good, experienced facilitator may counterbalance the deficits and biases listed above and has been suggested as a debiasing technique (Montibeller and von Winterfeldt 2015). Questioning, interactions among stakeholders, creativity techniques, and problem structuring methods can help uncover a wide range of objectives (Mingers and Rosenhead 2004; Neves et al. 2009; Keeney 2013; Lienert et al. 2015).

At the group level, the influence of group dynamics can become an issue. This manifests in several motivational and cognitive biases which can result in a narrow consideration of objectives (see Montibeller and von Winterfeldt 2018). Extensive research has been conducted on the advantages and disadvantages of various forms of group brainstorming and ideation in groups (e.g., Nijstad et al. 2002; Nijstad and Stroebe 2006; Paulus and Brown 2007; Litchfield 2008).

This study focuses solely on individuals. However, it is also relevant for group processes: eliciting objectives from individuals can be a preliminary activity to a group workshop or an activity within a workshop. This combination of individual and group activities might mitigate some of the group biases mentioned above and give a voice to individuals whose views might otherwise be neglected.

\subsection{Public level}

For a single decision maker, finding objectives is challenging, but still rather straightforward, since she or he will bear the decision's consequences. Group decisions are more complex due to the negotiated perspective on the decision problem. In public decisions, complexity increases further, as these decisions have impacts on many stakeholders (e.g. Keeney 1988).

There are two ideal-type approaches to public decision making. One relies on experts or representatives, such as a public agency, an engineering consultant, or an executive political body, who make decisions on the public's behalf. This has traditionally been a common way of governance (Meadowcroft 2004) and is also in line with the hydraulic logic of the water sector (see section 0). The public often remains anonymous and does not have explicitly articulated objectives. Therefore, assumptions about their values and preferences have to be made by the small group of decision makers. The second approach is more inclusive and in line with a sustainability paradigm (Meadowcroft 2004), which matches to the water-sensitive logic. Here, the stakeholders, especially the public, are more directly involved in the decision-making process, for instance by consultation or collaboration.

Both approaches require the generation of decision objectives. In the former, the decision makers need to consider not only their personal or organizational objectives but also those of 
others (e.g., citizens or future generations). In the latter, we need a way to elicit the decision objectives of many stakeholders. Both tasks are challenging. It can be difficult for decision makers to think broadly, include other people's interests, and consider less salient objectives. For broad public involvement, decision processes requiring physical presence can be a hindrance.

\section{Research objectives}

Eliciting decision objectives poses challenges on the individual, the group, and the public level (section 3). The overarching aim of this study was to investigate the generation of objectives by individuals in the context of public decisions. This meant (1) establishing whether individual brainstorming leads to insufficient objective generation in a real-world setting; (2) testing three interventions to improve the generation of objectives; (3) investigating which and how many stakeholders are necessary to generate a comprehensive set of objectives; and (4) developing a feasible procedure for practical use.

We developed an online survey procedure for eliciting objectives and applied this to five decision cases. The aim of the survey was to generate a set of objectives sufficiently comprehensive to also consider less salient issues. In the survey, participants received up to three interventions to help them generate objectives. Bond et al. (2010) tested a number of small interventions with this intention. These included providing sample objectives, providing category names, providing direct challenges to add more objectives, providing a master list - a comprehensive list of objectives - and warning participants that important objectives could be missing (Bond et al. 2010). For this study, we adopted the provision of category cues and the provision of a master list. In addition, we tested a perspective-taking task designed to broaden the set of objectives (section 5.2 ). We compared the effectiveness of the interventions with an experiment.

We investigate seven research questions:

1. How can we encourage the generation of a large number of objectives by individuals?

1A hypothesis: Prompting people to think about other perspectives and providing categories for objectives results in a larger number of objectives than unaided brainstorming.

1B hypothesis: People select more objectives from a master list of objectives than they generate by themselves in brainstorming tasks.

2. Are all the steps proposed in the survey necessary for generating a large number of objectives?

2A research question: At what step of the survey process were objectives first generated?

$2 \mathrm{~B}$ research question: What is the proportion of objectives not matched to master list objectives?

3. How can we encourage the generation of a broad set of objectives by individuals?

3A hypothesis: Prompting people to think about other perspectives and providing categories for objectives leads to a broader set of objectives compared to unaided brainstorming. 
3B hypothesis: The set of objectives obtained by selection from a master list pertains to more categories than when objectives are generated by brainstorming.

4. What is the perceived importance of objectives generated at different steps?

4A Research question: How is the importance of an objective related to the survey step it was generated at?

4B Hypothesis: Self-generated objectives are perceived as more important than recognized objectives.

5. What is the influence of stakeholder characteristics on their performance in objective generation and their perception of the objectives' importance?

6. Does asking more stakeholders result in more distinct objectives?

7. Which objectives and categories did participants perceive as important, and how is that related to the actual decision cases?

7A research question: Which objectives were perceived as important in the survey?

7B research question: Which categories do the most important objectives belong to?

7C research question: Are new objectives uncovered in the survey that, until that time, had not been prominent in the actual decision cases?

Questions 1, 2, and 4 have previously also been investigated by Bond et al. $(2008,2010)$. We were interested if their main findings could be replicated in complex planning decisions with participants who have substantial stakes in the decision and knowledge of the decision domain. Previous studies mostly relied on students who had to tackle personal decisions. This study also extends previous work by investigating the effectiveness of our interventions in broadening the range of the objectives generated. Furthermore, we compare our online elicitation with the actual objectives considered in the case studies. Research questions 3, 5, 6, and 7 are, to our knowledge, unique to this study.

\section{Methods}

\subsection{Decision cases and stakeholders}

Our research took place in the context of decision cases concerning regional planning of wastewater treatment in four cantons in Switzerland. One alternative in the discussion was the possible merger of wastewater treatment plants, as this can produce economies of scale (Abbott and Cohen 2009). This means that, instead of being treated at several plants, all the wastewater of a region would be routed to one treatment plant, which might be enlarged or built new.

In Switzerland, regional planning of infrastructure typically involves several organizational bodies, which establish a planning committee. A decision is sought in a multi-organizational group decision process. Usually, an engineering consultancy leads this process and provides technical expertise. Larger infrastructure decisions normally require approval by popular vote. Therefore, the planning committee is interested in the public opinion. 
The online survey for objective generation (section 5.5 ) was sent to stakeholders in five decision cases. For reasons of anonymity, we refer to these cases by the acronyms WI, OA, EN, GB, and RU (Table SI-1). The cases differed considerably in decision processes, type and number of involved actors, size, institutional arrangements, and local conditions, so their concrete decision problems also differed. The research team has been involved to different degrees in these cases from being a passive observer to leading the decision support process (Table SI-1).

In two cases, the survey participants were all members of the formal planning committees $(\mathrm{OA}$, WI). For three cases, additional participants were identified by stakeholder analysis (GB, RU, EN). Between March and June 2018, an email invitation was sent to 13-31 stakeholders per case: 92 stakeholders in total. The different cases stood at different points in the decision process (Table SI-1). All participants were connected to the decision problem in some form and thus were knowledgeable about the decision. However, not all had decision-making power. With some exceptions, participants included representatives of the wastewater associations or local politics, representatives of the regulatory agencies, engineering consultants, and technical personnel. We collected a range of data about these stakeholders, either directly in the cases or in the survey (see Table SI-2 for an overview).

\subsection{Improving the elicitation of objectives}

Using an online process. We set up the objective generation process as an online survey. This format has potential advantages that can make it more efficient than paper- or interaction-based approaches. Firstly, it can be completed at any time and place, independently of other people, as long as participants have access to a web browser. Secondly, it is anonymous, which can be beneficial in some instances (e.g. Pissarra et al. 2005). Thirdly, it is scalable and easily distributed to allow inclusion of a wider public. Potential disadvantages are the lack of interactivity with other people and the need for participants to be familiar with the technology.

Intervention 1: perspective taking. The decision makers in public decisions are usually representatives taking the decision on behalf of others. Thus, they need to consider the perspectives of other stakeholders, such as civil society, or even future generations. Taking the perspective of others can increase prosocial behavior and concerns for the environment (Schultz 2000; Pahl and Bauer 2013; Ku et al. 2015). Therefore, a promising intervention for better objective generation was to try to increase perspective taking by making it an explicit task.

Intervention 2: provision of categories. Because memory is associative, an idea tends to facilitate the retrieval of other similar ideas (Paulus and Brown 2007). Therefore, people can become stuck within a cluster of ideas and might have difficulty considering very different ideas. Category names can enhance the recall of items that belong to those categories (Tulving and Pearlstone 1966). In other studies, providing categories increased the number of objectives generated (Bond et al. 2010). The notion that participants generate more diverse ideas when exposed to items from a wide range of categories has also been observed in other contexts 
(Nijstad et al. 2002). Given these previous findings, the provision of category cues was a promising intervention.

Intervention 3: provision of a master list. A master list is a comprehensive set of objectives that may be relevant for a particular decision. Such a list can be a powerful intervention (Bond et al. 2008). This might be related to the relative cognitive ease of recognition versus the generation of new ideas. Essentially, the list allows objectives to be identified upon recognition of the semantic cue of an objective. Using this intervention required the development of such a list for sustainable urban water management decisions (see section 5.3 ).

\subsection{Development of a master list}

We created a master list of objectives for our decision contexts, which is appropriate for diverse decisions regarding wastewater infrastructure planning (Table SI-4). To build the list, we compiled objectives for urban water management from the literature (Table SI-3) and our own case studies. We performed an ad hoc search of the academic and grey literature dealing with assessments and decision making in urban water management. From this collection, we chose 35 objectives that might be important in our decision contexts. This list covers a range of objectives for strategic planning of wastewater treatment, such as mergers of treatment plants or system decentralization.

In the creation process, we had to make certain decisions. (1) While comprehensive, our list is broad rather than deep to spark diversity. Therefore, specific sub-objectives can be missing. For instance, the objective "good ecological state of water bodies" can be specified further by to the level of various organism groups considered in environmental assessment (e.g., Reichert et al. 2015). (2) Decision objectives can be framed from different points of view. One example is an emission versus an immission perspective (Freni et al. 2010). The former tries to minimize what is emitted to the environment. An example is "low input of phosphorous to a river". The latter minimizes the impact but is agnostic about the total amount. An example is "high river water quality". With some exceptions, we decided to take an immission perspective.

To avoid overwhelming participants with objectives that were clearly not relevant to their decision, we used two versions of the master list in the cases (see Table SI-1, Table SI-4). They had 25 objectives in common; four objectives were specific for list one, and six for list two.

\subsection{Categorization of objectives}

Since some objectives belong to the same abstract concepts, they can be grouped - most commonly in an objectives hierarchy. As we were in an early decision phase, and hierarchy building would require further steps (e.g. Marttunen et al. 2019), we simply clustered the objectives into categories.

Our grouping was informed by themes about sustainable urban water management. Firstly, the classic triple bottom line of sustainability: economics (costs, finance), environment (impacts 
to water, air, etc.), and social aspects (health, jobs, etc.). To account for such topics as intergenerational equity and long-term impacts, we added the category "future". Additionally, categories for resources (e.g. resource recovery), organization/governance (e.g., autonomy, codetermination), and technical/operational (e.g. flexibility) accounted for more specific aspects of the wastewater system. When assigning the participants' objectives to categories, a category for legal compliance (e.g. compliance with regulations) and "process" (for process objectives) was also used.

\subsection{Elicitation of objectives in an online survey}

We implemented the interactive online survey for elicitation with limesurvey ${ }^{1}$; a paper version is provided in the supporting information (SI-7). The survey design was responsive and allowed access from different devices (computer, tablet, mobile). The survey was conducted in German; all the questions, objectives, and category names in this paper have been translated.

The participants were led through a multipart survey process with interventions for the generation of objectives (Figure 1). Before the main survey, participants were asked to state the role in which they would answer the questions (e.g., mayor, engineer, private person), because their views might differ if they answer in their official capacity or privately.

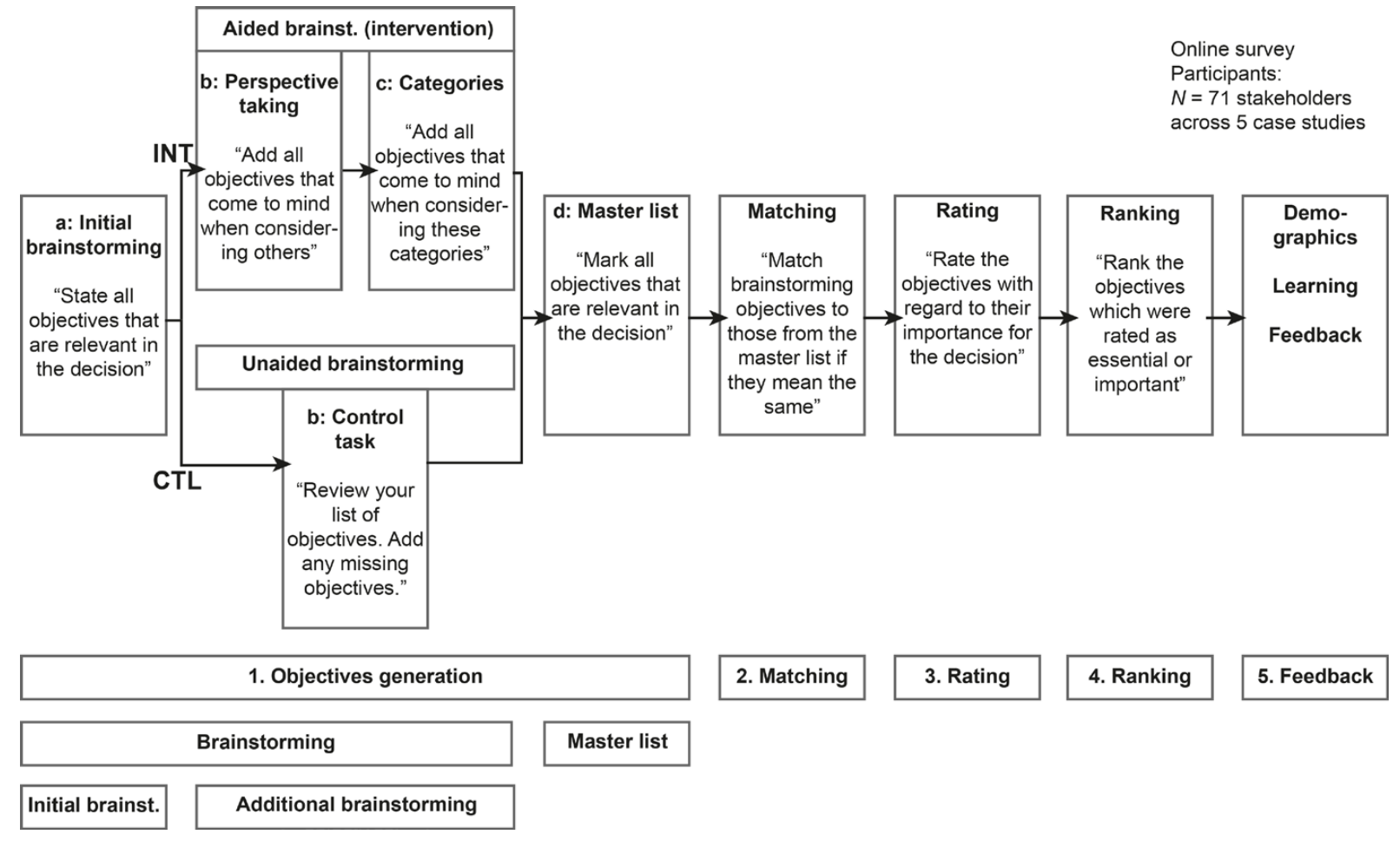

Figure 1: Logic and questions in the online elicitation of objectives. Participants were split into two groups by stratified sampling. Group INT (intervention) had some help with their brainstorming task, while group CTL (control) went through an unaided control task. The other tasks were the same for both groups.

${ }^{1}$ https://www.limesurvey.org/ 
1. Generating objectives: Participants first received a short explanation what an objective is and one example of an objective that is ubiquitous in these decisions: low annual costs. We judged that the danger of anchoring participants on this topic was preferable to participants not understanding what an objective is - as value-focused thinking is not familiar to all.

The first task for all participants (step 1a: initial brainstorming) was simple, open, and unaided brainstorming: they were asked to state all objectives that they considered important to the decision they were currently facing or had just faced. We started with an unaided question as a baseline, so we could test whether receiving guidance in brainstorming increases the number and breadth of objectives.

Next, we used stratified sampling 2 to split the participants into two groups. Participants in the intervention group (INT) received two aided brainstorming tasks for the objective generation steps (intervention), while the control group (CTL) simply had to review their list of objectives (control task). For the entire brainstorming phase, participants could see the objectives they had previously stated; only the explanatory text and questions changed.

For the INT group, the first aided brainstorming intervention was a short text requesting them to change their perspective (step INT $1 \mathrm{~b}$ in Figure 1). The text explained that wastewater systems serve important purposes and that changes to the system can affect others. Participants were asked to think of other people that might be affected in their municipality or region and add any objectives that came to mind considering these other perspectives. In the second aided brainstorming intervention (INT 1c), we presented six categories relevant to wastewater disposal (economic, environmental, resource, social, technical, and organizational objectives). We asked the INT participants to think about these categories and add any further objectives that came to mind.

In contrast, participants in group CTL were not offered either of these interventions. After the initial brainstorming (step 1a), they were shown a short text that asked them to review their list, think about it again, and add any missing objectives (CTL 1b).

After the brainstorming, we presented a master list of decision objectives to both groups (step 1d). The order of objectives was randomized. To avoid fatigue, we split the list at random and presented it on two consecutive survey pages. We asked the participants to carefully read every objective and mark all they considered relevant, no matter if they had already listed them before.

2. Matching objectives with the master list: We wanted to receive a comprehensive list of objectives for each participant with no duplicate objectives (termed final list). Therefore, we asked the participants to compare their stated objectives (steps 1a-c) and the objectives they had selected from the master list (step 1d). If they thought a stated objective essentially meant the same as an objective from the master list, they had to assign it to this objective via a drop-down

${ }^{2}$ For each case, participants were sorted by their functions and then assigned to a group. This prevented overrepresentation of one stakeholder type in one group (e.g., all engineers in one group and all authorities in the other). 
menu. By asking participants to do the matching themselves, we avoided misinterpretation by the researchers.

3. Rating the final list of objectives: Subsequently, participants rated the objectives from the final list on a five-point rating scale according to their perceived importance for the decision (4 essential, 3 important, 2 rather important, 1 rather not important, 0 not at all important). Because of range insensitivity bias such an assessment is conceptually problematic when the ranges of impacts are not defined (e.g., Von Nitzsch and Weber 1993; Montibeller and von Winterfeldt 2015). We interpreted the rating by the participants as an assessment of the salience of issues and rather than an importance weight of a preference model.

4. Ranking "essential" and "important" objectives: To differentiate the perceived importance of the objectives further, the participants ranked the objectives. First, they ranked all objectives which they had rated as "essential" in step 3. Then, they ranked all their "important" objectives. To save time, less important objectives were not ranked. The ranking is subject to the same conceptual problems as the rating when impact ranges are not defined (see above).

5. Learning, feedback, demographics: In the last survey part, we asked the participants about their roles, involvement in the decision process, and demographic data (Table SI-2). We also asked about perceived learning and for feedback on the survey.

\subsection{Data handling}

Terminology for sets of objectives

For each participant, the generated objectives were classified into six overlapping subsets following the matching procedure (see Figure SI-2 for an illustration). The following terminology is used in the remainder of the study (see Figure 1 for an explanation of the steps). (1) Objectives stated by participants in the brainstorming steps 1a-1b (CTL) or 1a-1c (INT): stated objectives. (2) Objectives selected at the master list, step 1d: selected objectives. In the matching, step 2, participants could map their stated objectives to one or several selected objectives and thus specify what they meant with their stated objectives. (3) The set of selected objectives that were assigned a stated objective and the stated objectives without a corresponding selected objective: self-generated objectives. Thus, the number of self-generated objectives can be higher than the number of stated objectives. (4) Selected objectives without a corresponding stated objective: recognized objectives. (5) The set of all self-generated and all recognized objectives: final list of objectives. (6) Objectives not selected from the master list: irrelevant objectives.

\section{Coding of objectives}

To compare the breadth of objectives, two researchers independently classified the stated objectives into the predefined categories (see section 5.4 ). The two researchers discussed discrepancies and then reached a common decision. Stated objectives without a corresponding selected objective could have been mentioned independently by different participants but 
actually mean the same. To avoid double counting, one researcher harmonized their formulation. In unclear cases, both objectives were kept.

\section{Generating a unique ranking}

Participants firstly ranked the objectives they rated "essential" and then the objectives they rated "important". To obtain a unique ranking, these rankings were combined. The less important objectives (rating: "rather important", "rather not important" or "not at all important") were not directly ranked by participants. We assigned ranks by competition ranking: Objectives which had been rated the same received the same ranking number (e.g., all "rather important" objectives received the same rank); thereafter, an equivalent gap was left in the ranking numbers.

\subsection{Statistical analysis}

\section{Statistical modelling}

To analyze the survey data and test our hypotheses, we used generalized linear models (Table 1). An alternative would have been the use of hypotheses tests, such as t-tests. However, generalized linear models allow us to handle the different data types (count, ordinal, censored, and longitudinal data) in a common framework and account properly for the error structures in the data (e.g. Bilder and Loughin 2014). All data analysis was performed in R (R Core Team 2018).

If the dependent variable was a count (e.g., number of objectives, number of categories), we used Poisson regression models (Bilder and Loughin 2014). If the dependent variable was a rating or ranking, we used proportional odds models, as implemented in the "ordinal" package (Christensen 2018). For analyses in which random effects due to participants should be accounted for, for instance in repeated measurements or rating, we used mixed effect models with a random intercept per participant (Agresti 2015). We give a full specification of the models in the supplementary information (SI-4).

For generalized linear models, the interpretation of parameters is generally not as straightforward as in linear regression. Since this study focuses on the significance of trends rather than sizes of effects, we refrain from detailed interpretation of parameters in the results section. In the following, we give a general intuition; a thorough treatment can be found in textbooks such as Bilder and Loughin (2014) or Agresti (2015).

In Poisson regression models, the exponential of a parameter - $\exp \left(\beta_{k}\right)$ - is the multiplicative term to use in calculating the estimated response when the predictor $x_{k}$ is increased by one unit while holding all the other predictors constant. This means that the effect of a change in the predictors depends on the level of the response variable. In proportional odds models, the parameter $\beta_{k}$ is the increase in log-odds of the response falling into or below any category when the predictor $x_{k}$ is increased by one unit while holding all the other predictors constant. In mixed models with random intercept, the random intercept term is included to account for variability between participants. For example, in a rating task, participants can have a different 
interpretation of the rating scale, so some participants might rate all items higher than others. The inclusion of a random intercept allows a general trend in the ratings to be estimated while accounting for participant-to-participant variability.

Table 1: Models used in the analysis. The full model specification is provided in the supporting information (SI-4: Models).

\begin{tabular}{|c|c|c|c|}
\hline Modelform & Type & Questions & Purpose \\
\hline Model-1-CTL & $\begin{array}{l}\text { Poisson generalized linear } \\
\text { mixed model with random } \\
\text { intercept }\end{array}$ & $1 \mathrm{~A}$ & $\begin{array}{l}\text { Relate the generation step to the number } \\
\text { of objectives/categories for control group }\end{array}$ \\
\hline Model-1-INT & $\begin{array}{l}\text { Poisson generalized linear } \\
\text { mixed model with random } \\
\text { intercept }\end{array}$ & $1 \mathrm{~A}$ & $\begin{array}{l}\text { Relate the generation step to the number } \\
\text { of objectives/categories for intervention } \\
\text { group }\end{array}$ \\
\hline Model-2 & $\begin{array}{l}\text { Poisson generalized linear } \\
\text { model }\end{array}$ & $1 \mathrm{~A}, 3 \mathrm{~A}$ & $\begin{array}{l}\text { Compare brainstorming between } \\
\text { intervention and control group }\end{array}$ \\
\hline Model-3 & $\begin{array}{l}\text { Poisson generalized linear } \\
\text { model }\end{array}$ & $1 \mathrm{~B}, 3 \mathrm{~B}$ & $\begin{array}{l}\text { Compare brainstorming to master list for } \\
\text { intervention and control group }\end{array}$ \\
\hline Model-4-CTL & $\begin{array}{l}\text { Proportional odds mixed } \\
\text { model with random intercept }\end{array}$ & $4 \mathrm{~A}$ & $\begin{array}{l}\text { Relate rating of objective to the generation } \\
\text { step for control group }\end{array}$ \\
\hline Model-4-INT & $\begin{array}{l}\text { Proportional odds mixed } \\
\text { model with random intercept }\end{array}$ & $4 \mathrm{~A}$ & $\begin{array}{l}\text { Relate rating of objective to the generation } \\
\text { step for intervention group }\end{array}$ \\
\hline Model-5 & $\begin{array}{l}\text { Proportional odds mixed } \\
\text { model with random intercept }\end{array}$ & $4 \mathrm{~B}$ & $\begin{array}{l}\text { Compare rating of self-generated and } \\
\text { recognized objectives }\end{array}$ \\
\hline Model-6 & Proportional odds model & $4 \mathrm{~B}$ & $\begin{array}{l}\text { Compare ranking of self-generated and } \\
\text { recognized objectives }\end{array}$ \\
\hline Model-7-SOC & $\begin{array}{l}\text { Poisson generalized linear } \\
\text { model }\end{array}$ & 5 & $\begin{array}{l}\text { Relate the number of } \\
\text { objectives/categories to socio- } \\
\text { demographic variables }\end{array}$ \\
\hline Model-7-FUN & $\begin{array}{l}\text { Poisson generalized linear } \\
\text { model }\end{array}$ & 5 & $\begin{array}{l}\text { Relate the number of } \\
\text { objectives/categories to stakeholder } \\
\text { functions }\end{array}$ \\
\hline Model-7-DEC & $\begin{array}{l}\text { Poisson generalized linear } \\
\text { model }\end{array}$ & 5 & $\begin{array}{l}\text { Relate the number of } \\
\text { objectives/categories to stakeholder roles } \\
\text { in decision making }\end{array}$ \\
\hline Model-8 & $\begin{array}{l}\text { Proportional odds mixed } \\
\text { model with random intercept }\end{array}$ & $7 \mathrm{~B}$ & $\begin{array}{l}\text { Relate rating of objective to the category it } \\
\text { belongs to }\end{array}$ \\
\hline
\end{tabular}

Relation to socio-demographic variables

We analyzed whether stakeholder characteristics could be linked to the number of objectives they generated or the number of categories these objectives belonged to. We analyzed the initial brainstorming task (step 1a, Figure 1) and the master list task (step 1d). Because these tasks were the same for both groups, this allowed the participants of INT and CTL to be pooled into a larger sample. We built three regression models that reflected our understanding of possible influences on objective generation (Model-7, Table 1). Additionally, we conducted a cluster analysis on the ratings of objectives, for which details are given in SI-5.2. 


\section{Saturation analysis}

Determining the number of stakeholders needed to cover the entire set of objectives is essentially a set cover problem. We implemented a greedy algorithm (Chvatal 1979) to find the minimum and maximum number of stakeholders required for each case.

\subsection{Comparison with the actual decision cases}

To relate the findings from the online survey to the real-world decision making, we compared which objectives were perceived as important in the survey and in the actual cases. Two cases, RU and GB (see section 5.1 for a description of the cases), were excluded from this analysis. The RU case was still at too early a stage for a comparison. For the GB case, the comparison was not meaningful, as the survey results were an input for the structuring of the actual objectives hierarchy.

We determined the decision objectives in the real-world cases using various sources of data. Naturally, such a process cannot be exhaustive, which means that some relevant objectives might have been missed. For the illustrative purposes of this study, we judged the level of detail sufficient.

For the OA case, a set of objectives for use in a decision model had been determined in a group process eight months prior to the online survey. All respondents to the online survey were part of this group. The researchers were also involved in this structuring process. In the EN and WI cases, the researchers were less directly involved. We determined the objectives based on public reports, press releases, and a video interview. The survey participants in case WI were the members of the planning committee. In the EN case, where we carried out the survey after a decision had been made, some participants were not active members of the planning committee. Therefore, new objectives might have been suggested by participants that had not had a voice in the actual planning.

\section{Results}

\subsection{Overview of responses and group similarity}

An email invitation was sent to 92 stakeholders. Across the five cases, the overall response rate was $84 \%$, with response rates of $100 \%$ in three cases (RU, WI, OA, Table SI-4). Of the total 77 responses, 71 could be used in the main analysis, accounting for drop-outs and exclusion of two answers. Of these 71, another three participants dropped out from the feedback or demographic parts (step 5, Figure 1). They were excluded only from the analyses that rely on these data. INT and CTL groups have similar key demographic characteristics (Figure SI-1). 


\subsection{Survey results}

\subsubsection{How can we encourage the generation of a large number of objectives by individuals?}

1A hypothesis: Prompting people to think about other perspectives and providing categories for objectives results in a larger number of objectives than unaided brainstorming.

Hypothesis $1 \mathrm{~A}$ is supported by our results, but the difference might not be relevant in practice. For the control group CTL $(N=33)$, the average number of objectives that participants had stated after the control task - "review your list and add any missing objectives" (step 1b, Figure 1) - was 3.5. After the initial unaided brainstorming (step 1a), they had stated 3.2 objectives on average (Figure 2). This difference was not significant $\left(\beta_{1}=0.08, p=.54\right.$; Model-1-CTL). In the control step, participants added 0.27 objectives on average. For the intervention group INT $(N=38)$, the average number of objectives that participants had stated after the additional aided brainstorming tasks (steps $1 \mathrm{~b}$ and $1 \mathrm{c}$ ) was 4.7. In the initial brainstorming (step 1a), they had stated 3.4 objectives on average (Figure 2). This difference was significant $\left(\beta_{1}=0.33, p=.005\right.$; Model-1-INT). In the perspective-taking task, the average number of added objectives was 0.71 and for the category task 0.61 objectives.

In direct comparison, after the initial brainstorming, participants on average added 0.27 objectives in the unaided brainstorming (group CTL), and 1.32 objectives in the aided brainstorming (group INT). This is a statistically significant difference $\left(\beta_{1}=1.57, p<.001, N=71\right.$; Model-2). However, while this difference is large in relative terms (factor 4.8 , since $\exp \left(\beta_{1}\right) \approx$ 4.8), from a practical standpoint, the absolute increases in objectives seem negligible for both groups (but see section 6.2.4).

$1 B$ hypothesis: People select more objectives from a master list of objectives than they generate by themselves in brainstorming tasks.

Our results support hypothesis 1B. Participants of the control group CTL on average stated 3.5 objectives in unaided brainstorming, and they selected on average 12.4 objectives from the master list (Figure 2). Participants of the intervention group INT on average stated 4.7 objectives in their aided brainstorming tasks, and they selected on average 12.3 objectives from the master list. Accordingly, for both groups the master list step was a significant predictor for a higher number of objectives relative to the brainstorming (CTL: $\beta_{1}=0.95, p<.001, N=38$ and INT: $\beta_{1}=$ $1.28, \mathrm{p}<.001, N=33$; Model-3). 


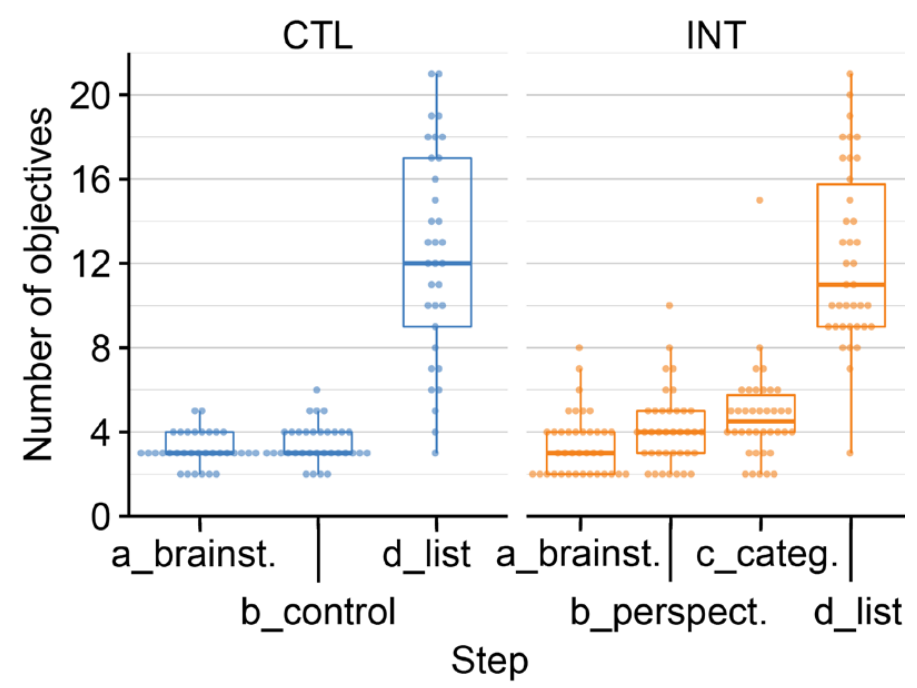

Figure 2: Number of objectives participants stated on their own (steps a-c) or selected from a master list (step d) in the survey steps (see Figure 1). Points represent individual participants. Boxplots show the $.25, .5$, and .75 quartiles of these data, and whiskers extend to the maximum and minimum points within 1.5 times the interquartile range. The numbers of objectives in steps $a, b$, and $c$ are cumulative as participants build upon the list of objectives they generated in the step before. a_brainst: initial brainstorming, step 1a; b_perspect: enlarging perspective ("by thinking of other affected people", step $1 \mathrm{~b}$ for group INT); c_categ: enlarging perspective ("by thinking of categories, e.g. environment", step 1c INT); b_control: review of list (step $1 \mathrm{~b}$ for group CTL); $\mathrm{d}_{-}$list: selection of objectives from a master list, step $1 \mathrm{~d}$.

\subsubsection{Are all the steps proposed in the survey necessary for generating a large number of objectives?}

$2 A$ research question: At what step of the survey process were objectives first generated?

In the matching (step 2, Figure 1), participants mapped their objectives from brainstorming to objectives they selected from the master list where possible. The objectives on the resulting final list were classified into self-generated objectives and recognized objectives (see section 5.6 for terminology). We investigated at which step of the survey each objective of the final list had first been generated.

Many participants identified a large portion of their final list at the initial brainstorming (Figure 3 and Table SI-8). Participants of the control group CTL on average identified 69\%, and participants of the intervention group INT on average identified $56 \%$ of their objectives at this step. Participants of the CTL group on average generated an additional 9\% of their objectives during the revision step (b_control, Figure 3 and Table SI-8). Consequently, on average they identified $22 \%$ of their objectives only when provided with the master list. Participants of the INT group on average generated an additional 7\% of their objectives during perspective taking (1b) and another $10 \%$ during the category task (1c) (Table SI-8). On average, INT participants recognized $27 \%$ of their objectives only from the master list (Figure 3).

Only eight participants of the CTL group (24\%) and six participants of the INT group (16\%) identified all their objectives in the brainstorming and did not identify new ones on the master list. Thus, brainstorming was not sufficient to elicit all objectives. Recognizing objectives from the 
master list was on average more successful than the additional brainstorming interventions (Figure 3 and Table SI-8), but the variation between participants was high. The results suggest that every step contributed to generating objectives. However, the study setup did not allow analysis of the individual effects of each intervention, only the effects conditional on the preceding steps.

At first glance, the finding that participants identified a large portion of their final list of objectives at the initial brainstorming seems to contradict the analysis in section 6.2.1 - which shows that participants generated much fewer objectives in the brainstorming phase than at the master list phase. This contradiction arises because often participants matched one of their stated objectives to several selected objectives. In this way, they could specify what they meant by their stated objective. Each selected objective that matched a stated objective was counted as selfgenerated. If we trust that participants were honest in their matching, this would mean that they already had these objectives in mind when brainstorming but could not articulate them properly. A function of the master list is thus to help them articulate these objectives better.

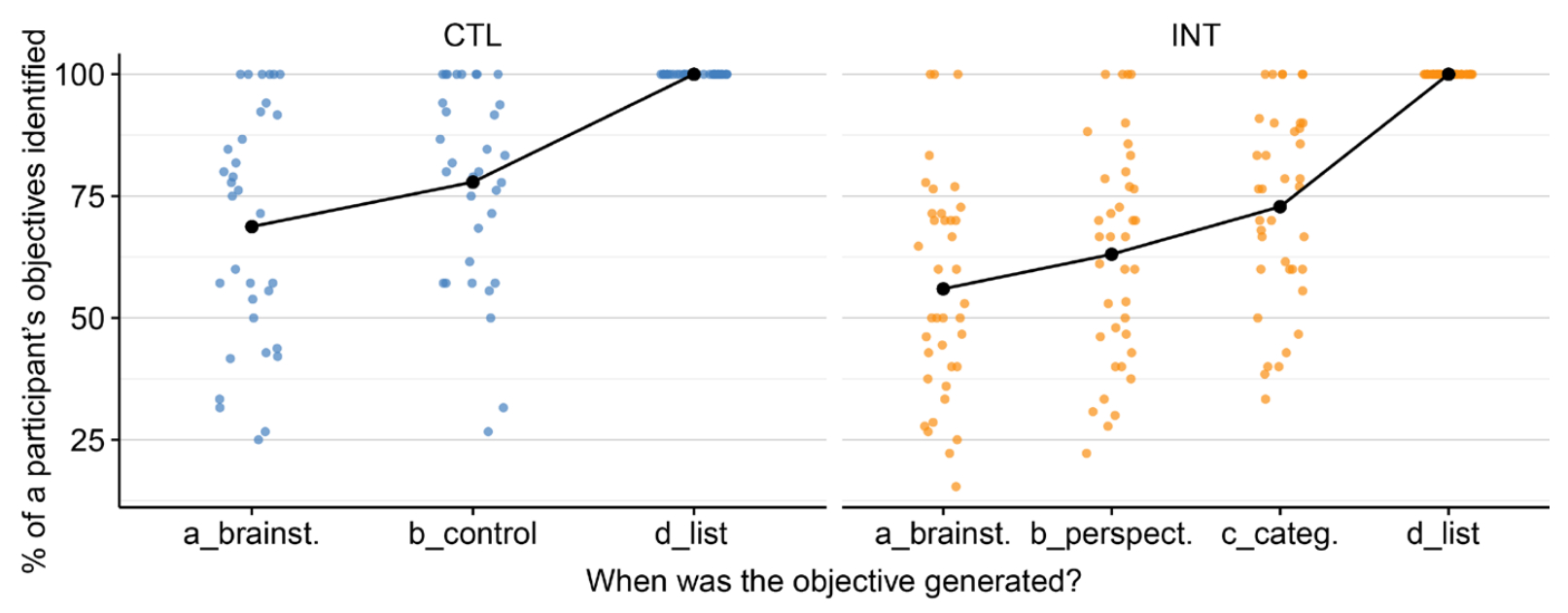

Figure 3: Percentage of objectives not already stated at an earlier step that were elicited at each step (1a-1d, Figure 1). Connected dots: average percentage across participants; individual dots: percentages of individual participants. CTL: control group; INT: intervention group.

\section{$2 B$ research question: What is the proportion of objectives not matched to master list objectives?}

Results of research question $2 \mathrm{~A}$ suggest that the master list was necessary to elicit all relevant objectives. However, our master list was not sufficient for all participants. For CTL, 9 of 33 participants $(27 \%)$ had one or more objectives in their final list that they could not match to the master list; for INT, the equivalent ratio was 14 of 38 (37\%). The maximum number of objectives a participant did not find on the master list was two in the CTL group and four in the INT group.

\subsubsection{How can we encourage the generation of a broad set of objectives by individuals?}

In both groups, the participants' objectives from the initial brainstorming (step 1a, Figure 1) could on average be mapped to approximatively three categories $(M=2.8$ for CTL, $M=2.9$ for INT; Figure 4). We examined the effect of the other interventions on the number of categories based on the stated objectives and selected objectives (see section 5.6 for terminology). 
3A hypothesis: Prompting people to think about other perspectives and providing categories for objectives leads to a broader set of objectives compared to unaided brainstorming.

Our results support hypothesis $3 \mathrm{~A}$, but the difference might not be relevant in practice. In the unaided control task for the CTL group (step 1b, CTL) on average 0.22 categories were newly registered, compared to 0.66 categories in the additional aided brainstorming of group INT (steps $1 \mathrm{~b}$ and $1 \mathrm{c}$ ) (Figure 4). While this difference is statistically significant $\left(\beta_{1}=1.10, p=.010, N=70\right.$; Model-2), the average number of categories added is less than one in both groups. Thus, the influence of these tasks appears to be small, especially when compared to the effect of the master list (see hypothesis 3B).

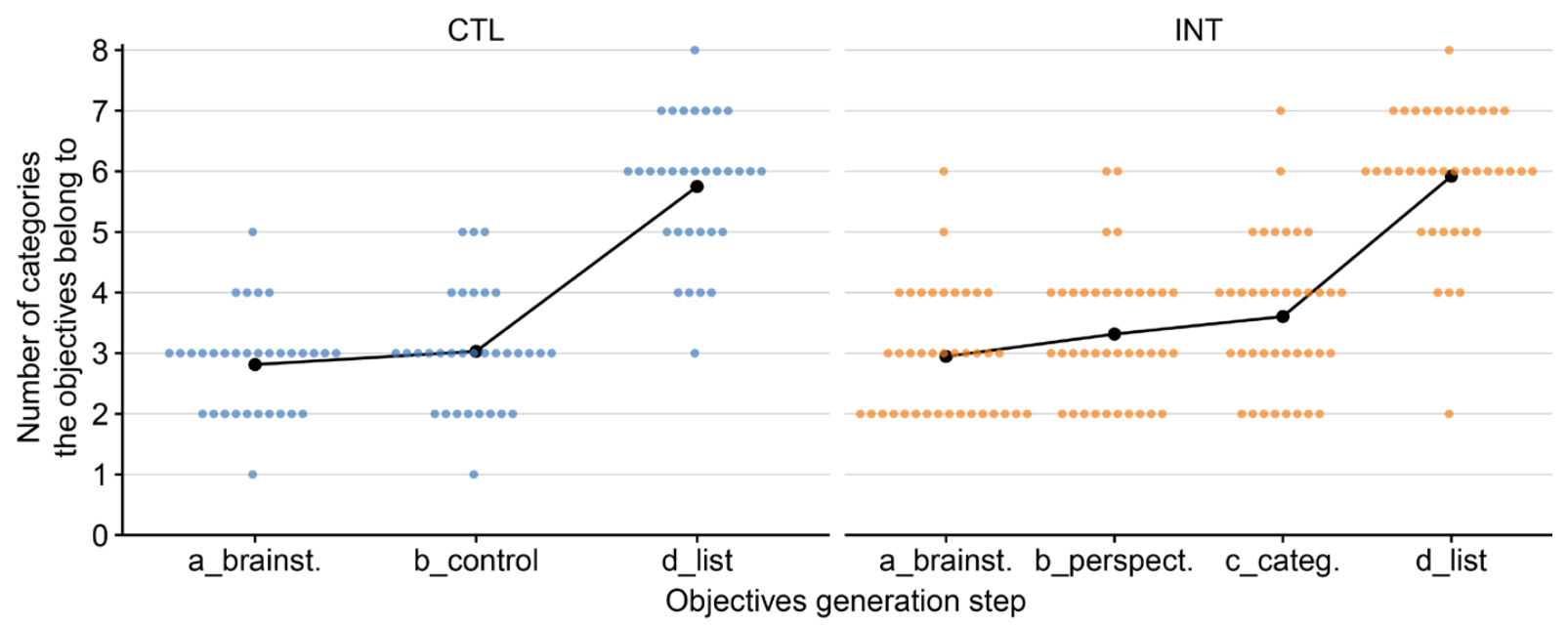

Figure 4: Number of distinct categories that can be assigned to the objectives stated in the brainstorming steps (a-c) and the objectives selected from the master list (step d) (see Figure 1 for an explanation of the steps). Points represent individual participants. For steps a, b, and c, participants built upon the list of objectives they generated in the step before.

\section{B hypothesis: The set of objectives obtained by selection from a master list pertains to more} categories than when objectives are generated by brainstorming.

Our analysis supports hypothesis 3B. When presented with the master list, participants on average identified 5.4 categories (CTL) and 5.3 categories (INT). At the end of the entire brainstorming, they had identified 3.0 categories (CTL; steps 1a-1b) and 3.6 categories (INT; steps 1a-1c) on average (Figure 4). Accordingly, for both groups, the master list step was a significant predictor for identifying more categories than brainstorming (CTL: $\beta_{1}=0.58, p<.001, N=32$; Model-3; INT: $\beta_{1}=0.38, p<.001, N=38$, Model-3). People produced a narrower range of objectives in the brainstorming than when choosing from the list.

When presented with the master list, participants on average identified an additional 2.3 categories (INT) or 2.7 categories (CTL) they had not identified in brainstorming before; in contrast, the additional aided brainstorming contributed little (see hypothesis $3 \mathrm{~A}$ ). Therefore, a broad consideration of objectives seems more easily achieved by presenting a master list than by improving brainstorming tasks. However, in the INT group 21 participants (55\%) and in the CTL group $10(31 \%)$ of the participants identified one or more categories during brainstorming that 
they did not identify in the master list. Often this category was about legal aspects. This again suggests that the approaches are complementary.

\subsubsection{What is the perceived importance of objectives generated at different steps?}

Based on objectives on the final list of objectives (see section 5.6 for terminology), which were rated and ranked, we analyzed at which step objectives with high perceived importance were generated. Firstly, we looked at the importance ratings. Secondly, we looked at the ranking data and highest-ranked objectives.

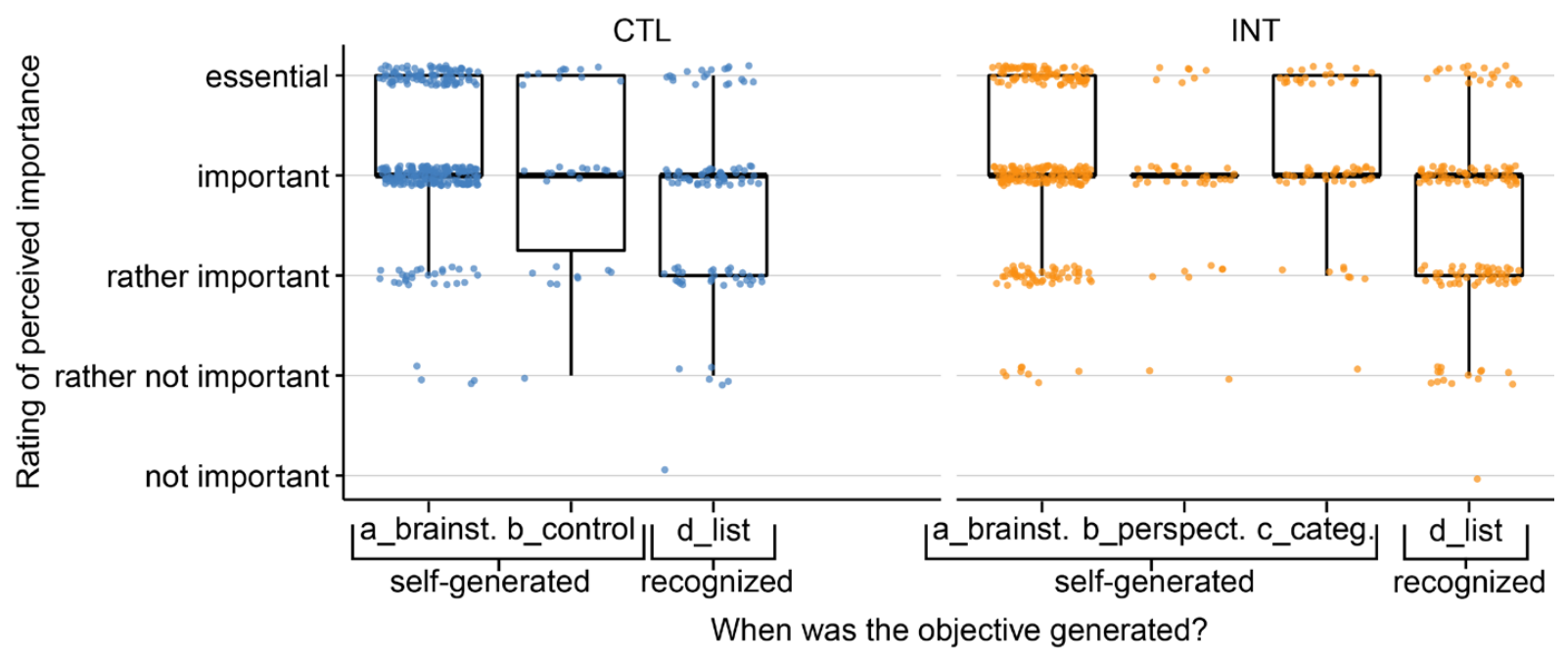

Figure 5: Rating of perceived importance of objectives that were generated at different steps (see Figure 1) on a five-point scale where $0=$ not important, and $4=$ essential. Dots represent individual evaluations; boxplots provide summary statistics of this information (see Figure 2 for further explanation).

4A Research question: How is the importance of an objective related to the survey step it was generated at?

For both groups, the distribution of the ratings for self-generated objectives appears similar, while recognized objectives receive a lower rating more often (Figure 5). Indeed, only the master list step (1d) was a significant predictor of the rated importance of objectives (group CTL: $\beta_{2}=-$ 1.441, $p<.001, N=33$, Model-4-CTL; group INT: $\beta_{3}=-1.163, p<.001, N=38$, Model-4-INT). This effect is negative, which means that recognized objectives were rated as less important than the self-generated objectives from the initial brainstorming. The perspective taking $(1 \mathrm{~b})$ and category (1c) steps for the intervention group INT were not significant predictors, neither was the unaided control step (1b) for the CTL group. Thus, the importance rating of objectives generated at these steps was not significantly different from the initial brainstorming.

We found somewhat different patterns when looking at the highest-ranked objectives. For the INT group, 25 of 38 participants (66\%) had generated their highest-ranked objective at the initial brainstorming step (1a), 1 (3\%) at the perspective-taking step (1b), 7 (18\%) at the category step (1c), and 5 (13\%) recognized it in the master list (step 1d). For CTL, these were 28 of 33 participants $(85 \%)$ in initial brainstorming, $2(6 \%)$ in the control task, and $3(9 \%)$ at the master 
list step. Thus, most participants had generated their highest-ranked objective at the initial brainstorming.

$4 B$ Hypothesis: Self-generated objectives are perceived as more important than recognized objectives.

In summary, our results support hypothesis 4B. For the first analysis, we pooled the selfgenerated objectives and the recognized objectives of both groups INT and CTL. Recognized objectives were associated with significantly lower ratings than self-generated objectives $\left(\beta_{1}=-\right.$ $1.24, p<.001, N=71$, Model-5). This is consistent with visual inspection (Figure 5) and the result obtained for question $4 \mathrm{~A}$.

Additionally, we used ranking data to corroborate our findings. The highest-ranked objective of 63 of 71 participants (89\%) was self-generated, while for 8 participants (11\%) it was recognized. Across both groups, on average $85 \%$ of a participant's top five objectives were selfgenerated objectives and 15\% were recognized objectives. However, half of the participants (33 of $71 ; 46 \%$ ) had one or more recognized objectives in their top five ranks.

Considering the five top-ranked objectives per participant, self-generated objectives were not ranked significantly higher than recognized objectives $\left(\beta_{1}=0.11, p=.69, N=66\right.$, Model-6). At first glance, this seems to contradict previous results. However, this analysis only showed that once a recognized objective had made it into the top five, it was not ranked significantly differently from a self-generated objective.

\subsubsection{What is the influence of stakeholder characteristics on their performance in objectives generation and their perception of the objectives' importance?}

We did not find strong effects that could explain the number of created or selected objectives with demographic and professional characteristics of the participants $(N=68)$. The number of stated objectives in the initial brainstorming had no significant (with $p<.05$ ) predictors in any of the models (Model-7, see section 5.7 ). For the selected objectives from the master list, we found small but statistically significant trends for six variables relative to the baseline. The time a person has lived in her or his municipality had a small negative effect on the number of objectives selected $\left(\beta_{5}=-.005, p=.010\right.$, Model-7-SOC); age had a small positive effect $\left(\beta_{2}=.078, p=.042\right.$, Model-7-SOC); being in the field of operations and maintenance had a positive effect ( $\beta_{7}=.291, p$ $=.043$, Model-7-FUN); and having a function in decision support or interest representation had a positive effect ( $\beta_{3}=.226, p=.021, \beta_{4}=.242, p=.041$, Model-7-DEC).

Using the same model structures as above, none of the demographic and professional characteristics were significant predictors (with $p<.05$ ) for the number of categories identified in initial brainstorming or obtained by selection from the master list.

We conducted a cluster analysis based on the ratings of selected objectives to explore the similarity of views as indicated by the perceived importance of objectives (see SI-5.2 for details). One proposition was that stakeholders within one case might cluster together, as issues differ in 
their prominence between cases. However, we did not detect clear relationships between the clusters of stakeholders and the stakeholders' characteristics.

\subsubsection{Does asking more stakeholders result in more distinct objectives?}

We observed a saturation effect. For each case, we determined the minimum and maximum number of participants necessary to generate the entire set of unique objectives generated in the survey (Figure 6). In each case, at least one prolific participant generated more than 20 objectives. As expected, the rate of finding new distinct objectives decreases because every additional participant adds fewer new objectives. The entire set of objectives can be covered by as few as five to nine participants, depending on the decision case (Figure $6 \mathrm{~A}$ ).

If we calculate the slowest way to cover the entire set of objectives and start with the participants who generated the least objectives, saturation occurred in only two cases, although the rate at which distinct objectives were generated decreases (Figure 6 B). Extrapolating these results, it seems that few additional objectives would be elicited if there were more than 20 participants.

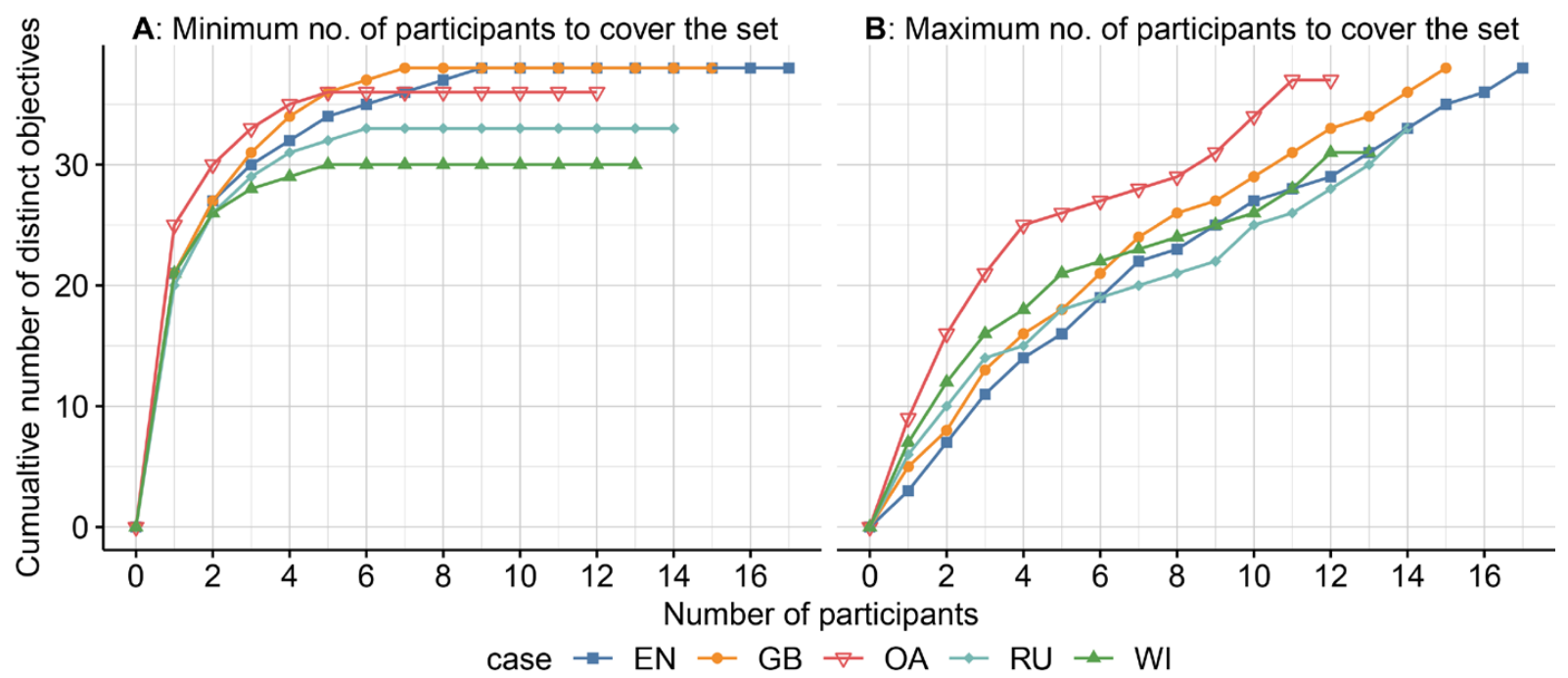

Figure 6: Number of participants necessary to generate the entire set of objectives. Y-axis: cumulative number of distinct objectives in each case, based on the final lists of objectives of the participants. Symbols represent the marginal contribution of each additional participant to this set, given the objectives previously generated by participants to the left on the $\mathrm{x}$-axis. A: participants are ordered by the maximum marginal contribution; B: participants ordered by the minimal marginal contribution to the full set.

\subsection{Reality check: Comparison of survey results to the actual decision cases}

$7 A$ research question: Which objectives were perceived as important in the survey?

We determined the seven most important objectives per case by calculating a weighted average $^{3}$ of the ratings that an objective on the final list received. Across all five cases, the ecological state of surface water (objective A) was seen as a key objective (Figure 7). Indeed, the actual decision cases often arose from a motivation to improve the protection of water bodies

3 To build this importance index, we treated the ordinal rating data as cardinal. We only used it to provide a general indication of perceived importance and not for quantitative comparison. 
(Table SI-1). As expected, certain objectives were more prominent in some cases than others (e.g., G: removal of micropollutants). Interestingly, a fair distribution of costs (D), which was perceived to be important in most cases, was sometimes perceived to be even more important than the objective low annual cost (B). Of the thirteen objectives in Figure 7, nine can be found in some form in legal guidelines or regulations (A, B, C, E, G, H, I, J, M). The other four go beyond legal provisions.

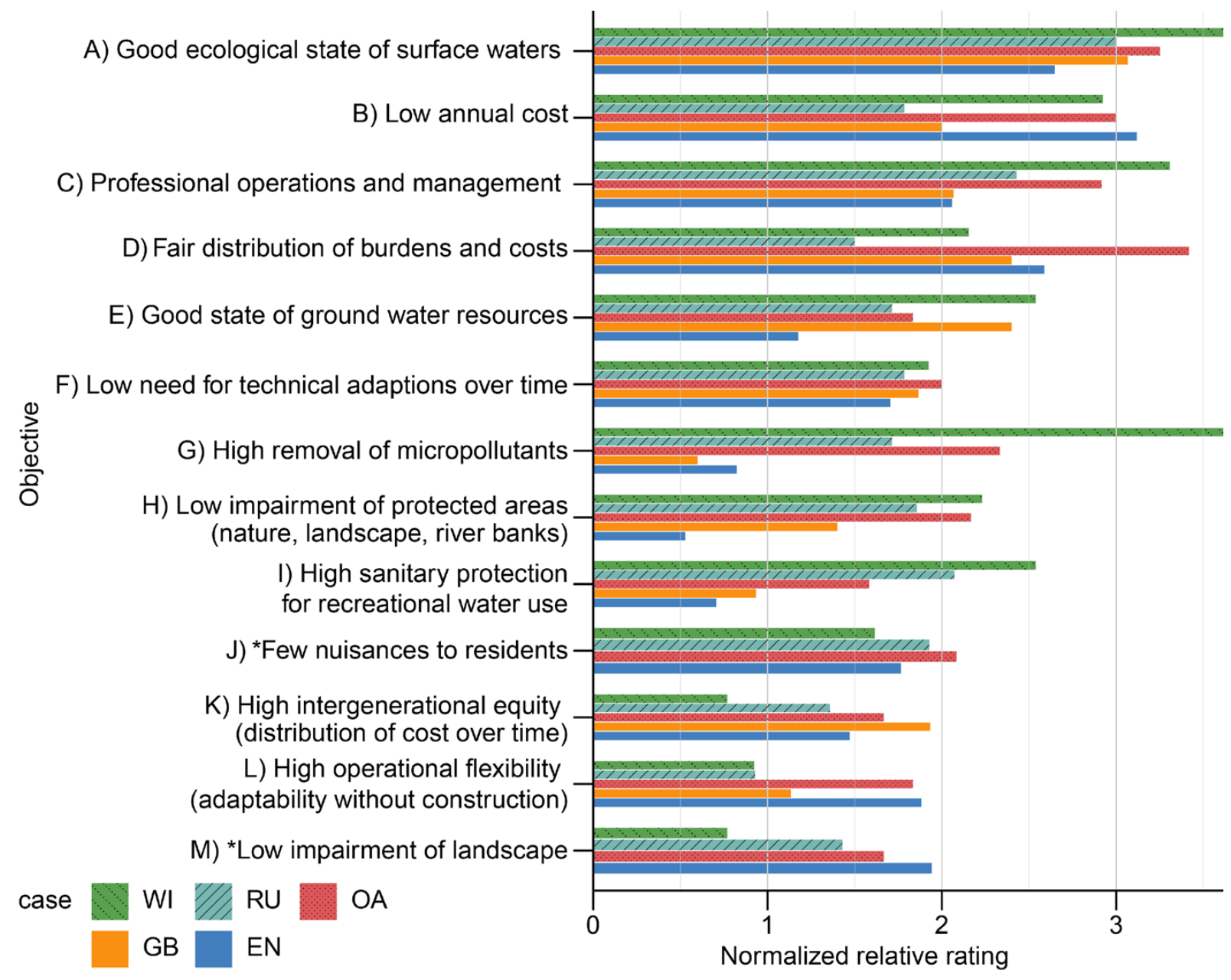

Figure 7: Rating index of the objectives that were among the top seven in at least one of the cases. Objectives with a star $\left({ }^{*}\right)$ were not part of master list 2 , therefore there is no rating for the GB case.

$7 B$ research question: Which categories do the most important objectives belong to?

Using the economic objectives category as the baseline condition, there were no significant differences between the importance ratings of objectives in this category and those in the environmental, legal, or social categories. However, objectives belonging to the future, organization/governance, resources, and technical/operational categories were associated with significantly lower ratings $\left(\beta_{2}=-0.91, p=.007, \beta_{3}=-1.29, p<.001, \beta_{5}=-1.53, p<.001, \beta_{7}=-0.63\right.$, $p=.010$ respectively; Model-8).

Similarly, objectives in the future, organization/governance, and resources categories were only rarely found among the top-ranked objectives (Figure SI-5). Environmental concerns dominated the top five ranks of the participants, followed by social, technical, and economic 
concerns. Note that the analysis of rankings is based on the final lists of participants. Since the number of objectives per category is not equal in the master lists (see Table SI-5), this could lead to a confounding effect.

7C research question: Are new objectives uncovered in the survey that, until that time, had not been prominent in the actual decision cases?

For three cases, we compared the top seven objectives as identified above from the online survey (Figure 7) with the objectives that played a visible role in the actual real-world decision making. Most of the objectives identified as important in the survey also played a role in the official case discussions (Table 2). We were interested in seeing which objectives surfaced as important in our survey but had not been discussed prominently in the actual decisions. In all three cases, this applied to the objective of professional operations and management (C). From informal discussions with stakeholders we know this is an issue in some situations, but it is rarely formulated as a decision objective. In two cases, the objective of fair distribution of cost (D) was identified in the survey, but not in the real case. Interestingly, this objective was even among those perceived to be most important in our survey. Apparently, this was a pressing issue for the participants but was not explicitly handled in the decision process. Additionally, the objective of water protection for recreational use (I) was not part of the official communication in the WI case. This seems justified, since it is unlikely to be impacted by the decision alternatives. The online survey process can be useful for drawing attention to objectives that might not otherwise receive sufficient attention.

Table 2: The seven most important objectives of our survey and their actual consideration in three case studies (see Table SI-1). The ranking of the objectives from our survey is given as number. Light shading of cells indicates that this objective was also part of the decision making or at least the official communication in the case. Dark shading indicates that this objective was identified in our survey, but did not play an apparent role in the actual decision-making discussions. Objectives not in the top seven for the case are unshaded.

\begin{tabular}{|c|c|c|c|c|}
\hline ID & Objective & $\begin{array}{l}\text { Rank } \\
\text { in EN }\end{array}$ & $\begin{array}{l}\text { Rank } \\
\text { in OA }\end{array}$ & $\begin{array}{l}\text { Rank } \\
\text { in WI }\end{array}$ \\
\hline A & Good ecological state of surface waters (rivers, lakes) & 2 & 2 & 1 \\
\hline B & Low annual cost & 1 & 3 & 4 \\
\hline $\mathrm{C}$ & $\begin{array}{l}\text { Professional operations and management (high } \\
\text { reliability, fast emergency response, good monitoring) }\end{array}$ & 4 & 4 & 3 \\
\hline $\mathrm{D}$ & Fair distribution of burdens and costs & 3 & 1 & \\
\hline $\mathrm{E}$ & Good state of ground water and spring water resources & & & 5 \\
\hline G & High removal of micropollutants & & 5 & 2 \\
\hline $\mathrm{H}$ & Low impairment of protected areas & & 6 & 7 \\
\hline I & $\begin{array}{l}\text { High sanitary protection for recreational water use (e.g., } \\
\text { swimming) }\end{array}$ & & & 6 \\
\hline $\mathrm{J}$ & Few nuisances to residents (noise, odor, traffic) & 7 & 7 & \\
\hline
\end{tabular}




\begin{tabular}{llccc}
\hline ID & Objective & $\begin{array}{c}\text { Rank } \\
\text { in EN }\end{array}$ & $\begin{array}{c}\text { Rank } \\
\text { in OA }\end{array}$ & $\begin{array}{c}\text { Rank } \\
\text { in WI }\end{array}$ \\
\hline L & High operational flexibility (adapt. without construction) & 6 & \\
\hline M & Low impairment of landscape & 5 & \\
\hline
\end{tabular}

\subsection{Evaluation of the online survey process}

Time required: We recorded the time spent on individual pages. Participants that spent more than 15 minutes on a single page were excluded from the analysis, as they likely kept the survey open in the browser without giving inputs. Participants of the control survey (CTL) spent 14 minutes on average on objective generation, rating, and ranking (steps 1-4); those with interventions (INT) 15 minutes (Figure SI-5). In both groups, participants spent five minutes on average on the other questions (step 5). This amounts to an average active survey time of roughly 20 minutes. However, the true total survey time was somewhat longer due to load times and time spent on the introductory page.

Ease of the survey: We asked several feedback questions on the process $(N=68)$. Forty-six participants $(68 \%)$ were certain or very certain that they could express their true opinion in the survey; four $(6 \%)$ were uncertain or very uncertain. Eighteen participants $(26 \%)$ found the survey easy, 39 (57\%) neither easy nor difficult, and 11 (16\%) difficult. No one considered the survey as very difficult or very easy. Of the 11 participants that considered the survey difficult (the other respondents had not been asked this question), 5 (45\%) found the ranking difficult, and $3(27 \%)$ the perspective taking and the matching (Table SI-8).

Of the 73 participants who answered the main parts of the survey, we identified two who had clearly misunderstood the survey task and were therefore excluded from the analysis. Instead of adding further objectives to their list in the brainstorming, they deleted their objectives from the previous steps and filled in new ones.

Learning: There were few incidents of self-reported learning concerning facts or preferences while going through the survey process. Of 66 participants answering these questions, eight $(12 \%)$ stated that they had gained new insights into wastewater disposal while filling in the survey. Two (3\%) stated that they had changed their opinion. These sparse incidents of reported learning occurred at different survey steps. We did not include other, more indirect ways of assessing learning in the survey.

\section{Discussion}

\subsection{How can we support individuals in generating objectives?}

\subsubsection{What interventions are effective in increasing the number of objectives?}

This study supports the notion that brainstorming is not enough for eliciting objectives and that providing a master list is a powerful additional intervention. While participants on average mentioned only four to five objectives in brainstorming (survey steps 1a-1c; Figure 3), they on 
average selected 12 objectives from the master list (step 1d). Participants matched their stated objectives to those selected from the master list (see section 5.6 for terminology). Given this matching, most participants had identified a large proportion of their final list of objectives $-62 \%$ on average across groups -already in the initial brainstorming (step 1a), but few participants identified all of their objectives. Across groups, on average $25 \%$ of objectives were only recognized from the master list. This is consistent with, but less extreme than, previous findings that in similar tasks more objectives were recognized than self-generated (Bond et al. 2008). The self-generated objectives were rated significantly more important than the recognized objectives (hypothesis 4B, Figure 5). However, 11\% of the participants, gave a recognized objective as their highest-ranked; they failed to generate their most important objective by brainstorming.

Participants often matched their stated objectives to several objectives from the master list. This indicates that the master list was also useful for participants to specify what they meant. Thus, a main function of the master list would be to help people in articulating what they want in addition to discovering new objectives. Our data do not allow us to infer whether participants actually had these objectives in mind, but were unable to articulate them fully, or whether the matching step helped them to realize what their stated objectives could mean. Therefore, the mapping might overstate the number of truly self-generated objectives.

A hasty conclusion would be that providing a master list might suffice for identifying objectives. However, about a third of the participants identified one or more objectives in unaided or aided brainstorming that were not on our list. Therefore, brainstorming also has value. A general list cannot cover all possible situations, and in most cases, it would be impossible to develop a more specified master list without intimate case knowledge - even though the purpose of eliciting objectives is precisely to identify this knowledge.

The master list's very effectiveness presents the risk that participants will not consider any objectives other than those listed. As with other methods, it is the responsibility of the analyst to provide a balanced view and not to implant his or her own ideas into the decision makers' minds. Compiling the master list from several sources, as in this study, can mitigate this risk. In our survey, on average $75 \%$ of participants' objectives were self-generated, which indicates that they did not rely solely on the master list or select many objectives that were not their own (Figure 3).

This part of our study corroborates the main results from the studies by Bond et al. (2008, 2010), but in a real-world context and with a broader study design and analysis approach. Decision makers have trouble articulating all their objectives and consistently fail to identify objectives on their own that they later identify as important. Provision of a master list is an effective way of improving the elicitation process. But as a master list can be insufficient for eliciting all relevant objectives, open brainstorming combined with a master list is a promising approach. 
We tested two further interventions for improving brainstorming. These prompted participants to think in different ways, by thinking of other affected people (step $1 \mathrm{~b}, \mathrm{INT}$ ), and thinking of categories (step 1c, INT). Together, these aided brainstorming interventions led to significantly more objectives than an unaided control task. However, the effect was small, with on average only 1.32 objectives added. The relative inefficacy of the category task (step 1c) was contrary to expectations (cf. Tulving and Pearlstone 1966; Bond et al. 2010). However, it did help 7 out of 38 participants (18\%) to generate their highest-ranked objective. In conclusion, both these interventions provide potential benefits, but since each appears small, they require balancing with the additional effort. However, these tasks might be further improved, as discussed in section 7.2 .

\subsubsection{What interventions are effective in increasing the breadth of objectives?}

A motivation for this study was to explore how to elicit a more diverse set of objectives, which has not been investigated previously. As discussed in section 0 , traditionally few objectives are considered in decision making for wastewater management. Considering a broader set of objectives may be decisive for transitioning to more sustainable infrastructure and to a more water-sensitive logic in management.

We measured the breadth of objectives by assigning them to categories and analyzing the number of categories. We found a significant positive contribution of aided brainstorming interventions to the breadth of objectives (group INT) compared to the unaided brainstorming (group CTL); however, this effect was marginal: on average less than one new category. Contrary to expectations, the category task (step 1c), which explicitly provided a range of categories to stimulate thinking, was not effective in increasing the breadth of concerns. Again, the master list was most effective by supporting participants to add on average around 2.5 more categories than the initial brainstorming (section 6.2.3). However, many participants identified one or more categories only during brainstorming and not from the master list (hypothesis 3B, section 6.2.3).

Overall, participants generated a diverse set of objectives with the survey. These objectives also extend beyond those stipulated in legal regulations (section 6.3 ). Some objectives were uncovered in the survey that were not salient in the actual decision cases. One difference between a survey format and group processes is anonymity (cf. Pissarra et al. 2005); however, further investigation is required to understand the reasons behind the differences (see section 7.5).

\subsection{Why was the identification of objectives insufficient?}

So far, we have limited insight into why participants fail to identify their objectives or why some interventions are more successful than others. All factors identified in the introduction (see 3.1 ) remain possible explanations.

(1) Unfamiliarity with the concept of objectives: In the decision cases, the researchers anecdotally observed alternative-focused thinking as the prevailing mode of discussion. It has 
been shown that groups using value-focused thinking generated both more, and more diverse, objectives (León 1999).

(2) Cognitive difficulty: As has been argued in section 3.1, the de novo generation of objectives is likely more difficult than selection from a list. The effectiveness of the master list in comparison to brainstorming might partly be explained by the relative fluency (cf. Alter and Oppenheimer 2009) of the recognition task in comparison to recall or ideation. In the terms of Tversky and Kahneman (1973), the availability of objectives in brainstorming is lower than when they are seen in a list. Selection from a list only requires a decision, while brainstorming requires the formulation of thoughts.

(3) Lack of motivation: Motivation could play a prominent role, as persistence can be an important determinant in these kinds of demanding tasks (Nijstad et al. 2010). In the interventions, essentially the same brainstorming task had to be repeated several times. The brainstorming interventions were delivered as simple and short text cues. In a survey setting, where there is a lot of text anyway, this might not be a sufficiently strong and motivating cue. There might be more motivating and engaging ways to deliver such interventions, for instance using gamification (Aubert and Lienert 2019).

(4) Contextual factors and institutional limits to thinking more broadly and deeply could contribute to an overly narrow mental representation of the decision problem. A possible explanation for the relatively narrow perspective in brainstorming is that the objectives usually considered in these wastewater decisions are seen as fixed within the institutional logic.

Hydraulic logic would predominantly consider economic objectives constrained by environmental regulation (see section 0). This is consistent with our results. Objectives in categories such as organization/governance and resources attracted lower ratings of perceived importance than the traditional legal, economic, or environmental objectives (research question 7B). However, social objectives also attracted higher ratings. In our experience, the discussions in the five decision cases and the narratives of engineering consultants focused closely on cost and economic efficiency. In this survey, while important, the cost and economic objectives were not perceived as the dominant concerns by the stakeholders (Figure 7, Figure SI-5). Similar observations have been made in other MCDA applications in the water sector (Scholten et al. 2015; Lienert et al. 2016).

\subsection{Is more stakeholder involvement required for the generation of objectives?}

We did not find strong influences of stakeholder characteristics, which we hypothesized to be relevant, on performance in objective generation. These characteristics could not explain the number of objectives generated nor the breadth of objectives at either the initial brainstorming step or the master list step (research question 5). No clear patterns emerged from the stakeholders' views, as expressed by ratings of objectives, that could be attributed to sectors, functions, or classic socio-demographic variables (see SI-5.2). 
We tentatively conclude that performance in objective generation and the perception of objectives' importance is linked more closely to individual traits, which we did not elicit, than to socio-demographic variables or professional roles and functions. The general ability to generate decision objectives might be a more personal trait, such as creativity (Shalley et al. 2004), or a matter of personal experience. However, due to the small sample size $(N=66)$, the statistical power to detect any effect is small. Therefore, it remains an open question which types of stakeholders should be involved if the aim is to have a large and diverse set of objectives.

Another explanation is that our stakeholder sample was too homogenous to detect any differences. As most participants had experience with the topics of wastewater management and were trained in a similar institutional logic, their thinking and perception of important objectives could well have been aligned. With a larger and more diverse sample, further research could investigate the relationship between stakeholder diversity and diversity in the decision objectives and seek better predictors for the contributions of stakeholders. This could be coupled to more formal stakeholder analyses (Lienert et al. 2013).

Not all participants contributed equally to the joint set of objectives in each case. We observed saturation in the number of distinct objectives generated by each additional survey participant (research question 6, Figure 6). There are diminishing returns to simply spreading the survey among more participants. At some point, this is unlikely to generate more distinctly different objectives. Based on our worst-case results, we tentatively conclude that a large and diverse, though perhaps not complete, set of objectives can be obtained with around 10 to 15 participants. However, as it is difficult to predict stakeholders' abilities to generate diverse sets of objectives from their characteristics (see above), we cannot recommend a specific threshold on the number of stakeholders.

Our results support the proposition that the inclusion of stakeholders should be done deliberately (Gregory 2016; de Gooyert et al. 2017). Of course, stakeholders' abilities to generate objectives are not the only or even the best reason for stakeholder involvement. Procedural justice demands that people be given a chance to provide their input into decision making for moral and normative reasons (Fiorino 1990; Meadowcroft 2004). We would therefore encourage public participation even if this does not contribute to uncovering new objectives.

\subsection{Developing a feasible online survey tool for the elicitation of objectives}

With this study, we introduced and tested an innovative tool that can easily be applied in practice. Public planning is facilitated by specifying a public good with concrete decision objectives. A more inclusive perspective on governance also requires involving or consulting a wider community of stakeholders (e.g., Meadowcroft 2004; De Brucker et al. 2013). Sectors such as wastewater have traditionally considered few externally given objectives. Broadening the range of stakeholders and the breadth of objectives considered is facilitated by useful procedures and tools for objective generation. 
In contrast to a paper-based or personal interaction-based approach (e.g., face-to-face interview, workshops), an online survey is straightforward to scale and thus adapt to a large audience. Elicitation can be personal, yet anonymized. Because no direct interaction with a facilitator is required, it is a low-cost starting point for more in-depth deliberation.

The survey was readily understood and completed correctly by almost every participant (see section 6.4 ). It took participants on average 15 minutes to generate their objectives. Using our process, participants identified between 30 and 38 distinct objectives per case (Figure 6). In addition, the important objectives were rather diverse (Figure 7). The developed master list (Table SI-3) is suited for a range of strategic decisions surrounding wastewater infrastructure and can be directly applied to similar decision cases. Overall this type of survey proved to be successful for the generation of a large and diverse set of objectives for such public decisions.

The study focused on individuals, as all ideas ultimately emerge from individuals' minds. However, the approach can be used within a group process or to include citizens in general (cf. Aubert and Lienert 2019). For instance, a group of decision makers might be interested in the objectives of the wider population in a municipality. We have found preliminary online surveys useful for preparing group discussions and interviews.

\subsection{Limitations, research needs, and generalizability}

As the study took place within the context and time line of five actual decision cases, its design had limitations. Conducting the survey at different phases of the decision cases (Table SI-1) might have had a confounding effect. We used an experimental setup that allowed us to investigate a broad range of questions with a relatively small sample size. This meant that the interventions were sequential in nature and not all combinations could be tested independently. Accordingly, some hypotheses relate to the joint effect of two interventions. To investigate the relative contributions of single interventions, further research could aim at separating their effects - for instance by reordering or isolating the survey elements.

With exception of Bond et al. $(2008,2010)$ and this study, empirical evidence is limited regarding effective means to support individuals in their generation of objectives. Improved understanding of the psychological mechanisms in the objective generation process would allow the design of more targeted interventions. However, a more pragmatic trial-and-error approach of testing new interventions could also be useful.

Our comparison of the survey results to real-world outcomes was only brief. The collected data does not allow us to infer why some objectives that were perceived as important in the survey were missing from the actual discussion in the cases. Understanding this discrepancy could be informed by a qualitative approach to inquiry. Generally, a more in-depth and systematic comparison of processes for generating objectives and the use of various tools in these processes would be insightful; this could, for instance, contrast the process used here with an interactive process in a group. Such research is also in line with proposals in behavioral operational research 
(Franco and Hämäläinen 2016). These questions can be approached both by experimental studies and by qualitative research.

In comparison to the diversity of public planning decisions and the stakeholders in those decisions, our sample of cases and stakeholders was small and rather homogenous. However, we surveyed stakeholders with different backgrounds and functions in five independent case studies with different settings; this increased the diversity in our sample. Strictly, our results are only valid for this particular sample. Still, we see no compelling reason why the general trends discovered in this study would be markedly different in other contexts. Our findings on the generation of objectives by individuals corroborate previous studies (see section 7.1.1), which were conducted on different decisions in other contexts. Planning in the wastewater sector is not fundamentally different from that in such sectors as energy, transport, waste, and drinking water. Therefore, more specific results might also be generalizable, for instance, regarding the influence of the number or characteristics of stakeholders on the generation of objectives. However, further research in other contexts will be valuable to distinguish general from context-dependent patterns.

\section{Conclusions}

Objectives play a multifaceted role in both formal and informal decision-making processes (Keeney 1988; Keeney 2013). They provide the criteria against which decision alternatives are evaluated, they can inform the generation of alternatives (Keeney 1992), and they can help capture and synthesize the views of many stakeholders (Gregory 2016). While the paramount importance of objectives in decision making is well established, the generation and elicitation of objectives remains a challenge.

The first contribution of this study is to confirm the observation of Bond et al. $(2008,2010)$ that decision makers do not articulate all their objectives when simply asked to state them. This was the case even though the participants in our study were involved in a real-world decision process and the stakes were considerable. There was no relationship between the participants' experience with the decision topic and their performance in the generation of objectives. Simple brainstorming - asking "what do you want?" - is not sufficient for eliciting objectives effectively. Instead, we should provide cues to decision makers to broaden and deepen their thinking.

The second contribution of this study is the test of three interventions to aid decision makers. Our results lead us to believe that a process of simple brainstorming combined with the selection of objectives from a list and a matching of these objectives is simple but effective for obtaining a list of objectives for each stakeholder. Such a list of objectives is only the starting point of an objective structuring process (e.g., Keeney 2013; Marttunen et al. 2019). In the converging phase of such a structuring process, the number or breadth of objectives might be reduced again. However, this first step will influence all subsequent analyses. In our cases, some of the objectives identified in the survey were not explicitly identified in the actual decision-making processes. But 
whether the objectives generated with such a survey procedure are "better" or lead to other decisions is a question for further study.

The third contribution of this study is on the topic of stakeholder involvement. Stakeholder involvement in decision making is usually beneficial, although drawbacks have also been discussed (Fiorino 1990; Gregory 2016; de Gooyert et al. 2017). If we are interested in consulting stakeholders in objective generation only for substantive reasons (Fiorino 1990) - that their involvement should result in a more comprehensive set of objectives - the results of this study raised doubts. We observed that between five to nine participants were sufficient to generate the entire set of objectives in each case. Of course, several other compelling reasons remain for stakeholder involvement (e.g., Meadowcroft 2004; Gregory et al. 2012). The expertise or the function of the stakeholders had no identifiable effect on the number or breadth of objectives they generated or their perceived importance. However, the diversity in our sample was limited, so investigating the benefits of involving stakeholders remains an interesting open question.

A practical contribution of this study is the development of an online tool that should facilitate the generation and elicitation of a comprehensive set of objectives by a wide range of stakeholders. As demonstrated, the elicitation of objectives can be implemented through an online survey, which allows distributed collection of inputs from a large number of people. Our application showed that this is a feasible procedure. Overall, participants jointly identified between 30 and 38 distinct objectives for each case, and these also go beyond traditionally used legal objectives.

While our application cases were in wastewater infrastructure planning, we see no reason why the main results would differ in other sectors with similar characteristics. However, ample room remains for exciting research about eliciting decision objectives based on this and other studies. An increased awareness of the limitations of individuals in generating objectives and more research in improving this process can contribute to better decision objectives and, ultimately, better decision making.

\section{Acknowledgements}

We thank the organizations and stakeholders from the case studies for their participation and appreciate their openness to research. We are grateful to Philipp Beutler, Alice Aubert, and Marius Schneider for their contributions to this study. In addition, we thank the four anonymous reviewers for their helpful comments. We appreciate the financial support for this work by Eawag's Discretionary Funds granted by the Eawag Directorate.

\section{Supplementary information}

Supplementary material associated with this article can be found at https://www.sciencedirect.com/science/article/pii/S0377221719304771 


\section{References}

Abbott, M., and Cohen, B. 2009. 'Productivity and efficiency in the water industry', Utilities Policy, 17: 233244. https://doi.org/10.1016/j.jup.2009.05.001

Agresti, A. 2015. Foundations of linear and generalized linear models (John Wiley \& Sons Inc.: Hoboken, New Jersey).

Alter, A.L., and Oppenheimer, D.M. 2009. 'Uniting the Tribes of Fluency to Form a Metacognitive Nation', Personality and Social Psychology Review, 13: 219-235. https://doi.org/10.1177/1088868309341564

Anderson, N., Potočnik, K., and Zhou, J. 2014. 'Innovation and Creativity in Organizations: A State-of-theScience Review, Prospective Commentary, and Guiding Framework', Journal of Management, 40: 1297-1333. https://doi.org/10.1177/0149206314527128

Aubert, A.H., and Lienert, J. 2019. 'Gamified online survey to elicit citizens' preferences and enhance learning for environmental decisions', Environmental Modelling \& Software, 111: 1-12. https://doi.org/10.1016/j.envsoft.2018.09.013

Balkema, A.J., Preisig, H.A., Otterpohl, R., and Lambert, F.J.D. 2002. 'Indicators for the sustainability assessment of wastewater treatment systems', Urban Water, 4: 153-161. https://doi.org/10.1016/S1462-0758(02)00014-6

Bilder, C.R., and Loughin, T.M. 2014. Analysis of categorical data with R (CRC Press).

Bond, S.D., Carlson, K.A., and Keeney, R.L. 2008. 'Generating Objectives: Can Decision Makers Articulate What They Want?', Management Science, 54: 56-70. https://doi.org/10.1287/mnsc.1070.0754

Bond, S.D., Carlson, K.A., and Keeney, R.L. 2010. 'Improving the Generation of Decision Objectives', Decision Analysis, 7: 238-255. https://doi.org/10.1287/deca.1100.0172

Bousfield, W.A. 1953. 'The Occurrence of Clustering in the Recall of Randomly Arranged Associates', The Journal of General Psychology, 49: 229-240. https://doi.org/10.1080/00221309.1953.9710088

Brown, R.R., and Farrelly, M.A. 2009. 'Delivering sustainable urban water management: a review of the hurdles we face', Water Science and Technology, 59: 839-846. https://doi.org/10.2166/wst.2009.028

Brown, R.R., Keath, N., and Wong, T.H. 2009. 'Urban water management in cities: historical, current and future regimes', Water Science and Technology, 59: 847-855. https://doi.org/10.2166/wst.2009.029

Brownlow, S.A., and Watson, S.R. 1987. 'Structuring Multiattribute Value Hierarchies', Journal of the Operational Research Society, 38: 309-317. https://doi.org/10.2307/2582054

Christensen, R.H.B. 2018. 'ordinal: Regression Models for Ordinal Data', R package version 2018.8-25. https://CRAN.R-project.org/package $=$ ordinal

Chvatal, V. 1979. 'A Greedy Heuristic for the Set-Covering Problem', Mathematics of Operations Research, 4: 233-235. https://doi.org/10.1287/moor.4.3.233

De Brucker, K., Macharis, C., and Verbeke, A. 2013. 'Multi-criteria analysis and the resolution of sustainable development dilemmas: A stakeholder management approach', European Journal of Operational Research, 224: 122-131. https://doi.org/10.1016/j.ejor.2012.02.021

De Gooyert, V., Rouwette, E., Van Kranenburg, H., and Freeman, E. 2017. 'Reviewing the role of stakeholders in Operational Research: A stakeholder theory perspective', European Journal of Operational Research, 262: 402-410. https://doi.org/10.1016/i.ejor.2017.03.079

Fiorino, D.J. 1990. 'Citizen participation and environmental risk - a survey of institutional mechanisms', Science Technology \& Human Values, 15: 226-243. https://doi.org/10.1177/016224399001500204

Ford, C.M. 1996. 'A Theory of Individual Creative Action in Multiple Social Domains', Academy of Management Review, 21: 1112-1142. https://doi.org/10.5465/amr.1996.9704071865

Franco, L.A., and Hämäläinen, R.P. 2016. 'Behavioural operational research: Returning to the roots of the OR profession', European Journal of Operational Research, 249: 791-795. https://doi.org/10.1016/j.ejor.2015.10.034

Freni, G., Mannina, G., and Viviani, G. 2010. 'Emission standards versus immission standards for assessing the impact of urban drainage on ephemeral receiving water bodies', Water Science and Technology, 61: 1617-1629. https://doi.org/10.2166/wst.2010.887

Fuenfschilling, L., and Truffer, B. 2014. 'The structuration of socio-technical regimes-Conceptual foundations from institutional theory', Research Policy, 43: 772-791. https://doi.org/10.1016/j.respol.2013.10.010

Gregory, R., Failing, L., Harstone, M., Long, G., Mcdaniels, T., and Ohlson, D. 2012. Structured decision making: a practical guide to environmental management choices (Wiley-Blackwell: Chichester, West Sussex; Hoboken, N.J.).

Gregory, R.S. 2016. 'The Troubling Logic of Inclusivity in Environmental Consultations', Science, Technology, \& Human Values, 42: 144-165. https://doi.org/10.1177/0162243916664016 
Gruenewald, P.J., and Lockhead, G.R. 1980. 'The free recall of category examples', Journal of Experimental Psychology: Human Learning and Memory, 6: 225-240. https://doi.org/10.1037/0278-7393.6.3.225

Harris-Lovett, S., Lienert, J., and Sedlak, D. 2018. 'Towards a New Paradigm of Urban Water Infrastructure: Identifying Goals and Strategies to Support Multi-Benefit Municipal Wastewater Treatment', Water, 10: 1127. https://doi.org/10.3390/w10091127

Keeney, R.L. 1988. 'Structuring Objectives for Problems of Public-Interest', Operations Research, 36: 396405. https://doi.org/10.1287/opre.36.3.396

Keeney, R.L. 1992. Value-focused thinking: a path to creative decisionmaking (Harvard University Press: Cambridge, Mass.).

Keeney, R.L. 2013. 'Identifying, prioritizing, and using multiple objectives', EURO Journal on Decision Processes, 1: 45-67. https://doi.org/110.1007/s40070-013-0002-9

Kirschner, P.A., and Kirschner, F. 2012. 'Mental Effort.' in Norbert M. Seel (ed.), Encyclopedia of the Sciences of Learning (Springer US: Boston, MA).

Ku, G., Wang, C.S., and Galinsky, A.D. 2015. 'The promise and perversity of perspective-taking in organizations', Research in Organizational Behavior, 35: 79-102. https://doi.org/10.1016/j.riob.2015.07.003

Lai, E., Lundie, S., and Ashbolt, N.J. 2008. 'Review of multi-criteria decision aid for integrated sustainability assessment of urban water systems', Urban Water Journal, 5: 315-327. https://doi.org/110.1080/15730620802041038

Larsen, T.A., Hoffmann, S., Lüthi, C., Truffer, B., and Maurer, M. 2016. 'Emerging solutions to the water challenges of an urbanizing world', Science, 352: 928-933. https://doi.org/110.1126/science.aad8641

León, O.G. 1999. 'Value-Focused Thinking versus Alternative-Focused Thinking: Effects on Generation of Objectives', Organizational Behavior and Human Decision Processes, 80: 213-227. https://doi.org/10.1006/obhd.1999.2860

Lienert, J., Duygan, M., and Zheng, J. 2016. 'Preference stability over time with multiple elicitation methods to support wastewater infrastructure decision-making', European Journal of Operational Research, 253: 746-760. https://doi.org/110.1016/j.ejor.2016.03.010

Lienert, J., Schnetzer, F., and Ingold, K. 2013. 'Stakeholder analysis combined with social network analysis provides fine-grained insights into water infrastructure planning processes', Journal of Environmental Management, 125: 134-148. https://doi.org/10.1016/i.jenvman.2013.03.052

Lienert, J., Scholten, L., Egger, C., and Maurer, M. 2015. 'Structured decision-making for sustainable water infrastructure planning and four future scenarios', EURO Journal on Decision Processes, 3: 107-140. https://doi.org/10.1007/s40070-014-0030-0

Litchfield, R.C. 2008. 'Brainstorming Reconsidered: A Goal-Based View', Academy of Management Review, 33: 649-668. https://doi.org/10.5465/amr.2008.32465708

Markard, J. 2011. 'Transformation of Infrastructures: Sector Characteristics and Implications for Fundamental Change', Journal of Infrastructure Systems, 17: 107-117. https://doi.org/10.1061/(ASCE)IS.1943-555X.0000056

Marttunen, M., Haag, F., Belton, V., Mustajoki, J., and Lienert, J. 2019. 'Methods to inform the development of concise objectives hierarchies in Multi-Criteria Decision Analysis', European Journal of Operational Research. https://doi.org/10.1016/i.ejor.2019.02.039

Marttunen, M., Lienert, J., and Belton, V. 2017. 'Structuring problems for Multi-Criteria Decision Analysis in practice: A literature review of method combinations', European Journal of Operational Research, 263: 1-17. https://doi.org/10.1016/i.ejor.2017.04.041

Meadowcroft, J. 2004. 'Participation and sustainable development: modes of citizen, community and organisational involvement.' in William M. Lafferty (ed.), Governance for Sustainable Development: The Challenge of Adapting Form to Function (Edward Elga Publishing Ltd: Cheltenhan, UK).

Mingers, J., and Rosenhead, J. 2004. 'Problem structuring methods in action', European Journal of Operational Research, 152: 530-554. https://doi.org/10.1016/S0377-2217(03)00056-0

Montibeller, G., and Belton, V. 2006. 'Causal maps and the evaluation of decision options-a review', Journal of the Operational Research Society, 57: 779-791. https://doi.org/10.1057/palgrave.jors.2602214

Montibeller, G., and Von Winterfeldt, D. 2015. 'Cognitive and motivational biases in decision and risk analysis', Risk Analysis, 35: 1230-1251. https://doi.org/10.1111/risa.12360

Montibeller, G., and Von Winterfeldt, D. 2018. 'Individual and Group Biases in Value and Uncertainty Judgments.' in Luis C. Dias, Alec Morton and John Quigley (eds.), Elicitation: The Science and Art of Structuring Judgement (Springer International Publishing: Cham).

Neves, L.P., Dias, L.C., Antunes, C.H., and Martins, A.G. 2009. 'Structuring an MCDA model using SSM: A case study in energy efficiency', European Journal of Operational Research, 199: 834-845.

https://doi.org/10.1016/j.ejor.2009.01.053 
Nijstad, B.A., De Dreu, C.K.W., Rietzschel, E.F., and Baas, M. 2010. 'The dual pathway to creativity model: Creative ideation as a function of flexibility and persistence', European Review of Social Psychology, 21: 34-77. https://doi.org/10.1080/10463281003765323

Nijstad, B.A., and Stroebe, W. 2006. 'How the Group Affects the Mind: A Cognitive Model of Idea Generation in Groups', Personality and Social Psychology Review, 10: 186-213. https://doi.org/10.1207/s15327957pspr10031

Nijstad, B.A., Stroebe, W., and Lodewijkx, H.F.M. 2002. 'Cognitive stimulation and interference in groups: Exposure effects in an idea generation task', Journal of Experimental Social Psychology, 38: 535-544. https://doi.org/10.1016/S0022-1031(02)00500-0

Pahl, S., and Bauer, J. 2013. 'Overcoming the Distance: Perspective Taking With Future Humans Improves Environmental Engagement', Environment and Behavior, 45: 155-169. https://doi.org/10.1177/0013916511417618

Paulus, P.B., and Brown, V.R. 2007. 'Toward More Creative and Innovative Group Idea Generation: A Cognitive-Social-Motivational Perspective of Brainstorming', Social and Personality Psychology Compass, 1: 248-265. https://doi.org/10.1111/j.1751-9004.2007.00006.x

Payne, J.W., Bettman, J.R., and Schkade, D.A. 1999. 'Measuring constructed preferences: Towards a building code', Journal of Risk and Uncertainty, 19: 243-270. https://doi.org/10.1023/A:1007843931054

Pissarra, J., Gil, F., and Jesuino, J.C. 2005. 'Idea generation through computer-mediated communication', Journal of Managerial Psychology, 20: 275-291. https://doi.org/10.1108/02683940510589055

R Core Team. 2018. $R$ : A Language and Environment for Statistical Computing, Version 3.3.1 (R Foundation for Statistical Computing: Vienna, Austria).

Reichert, P., Langhans, S.D., Lienert, J., and Schuwirth, N. 2015. 'The conceptual foundation of environmental decision support', Journal of Environmental Management, 154: 316-332. https://doi.org/10.1016/i.jenvman.2015.01.053

Scholten, L., Schuwirth, N., Reichert, P., and Lienert, J. 2015. 'Tackling uncertainty in multi-criteria decision analysis - An application to water supply infrastructure planning', European Journal of Operational Research, 242: 243-260. https://doi.org/10.1016/j.ejor.2014.09.044

Schultz, P.W. 2000. 'New Environmental Theories: Empathizing With Nature: The Effects of Perspective Taking on Concern for Environmental Issues', Journal of Social Issues, 56: 391-406. https://doi.org/10.1111/0022-4537.00174

Shalley, C.E., Zhou, J., and Oldham, G.R. 2004. 'The Effects of Personal and Contextual Characteristics on Creativity: Where Should We Go from Here?', Journal of Management, 30: 933-958. https://doi.org/10.1016/i.jm.2004.06.007

Spiller, M. 2016. 'Adaptive capacity indicators to assess sustainability of urban water systems - Current application', Science of The Total Environment, 569-570: 751-761. https://doi.org/10.1016/j.scitotenv.2016.06.088

Stamm, C., Eggen, R.I.L., Hering, J.G., Hollender, J., Joss, A., and Schärer, M. 2015. 'Micropollutant Removal from Wastewater: Facts and Decision-Making Despite Uncertainty', Environmental Science \& Technology, 49: 6374-6375. https://doi.org/10.1021/acs.est.5b02242

Tulving, E., and Pearlstone, Z. 1966. 'Availability versus accessibility of information in memory for words', Journal of Verbal Learning and Verbal Behavior, 5: 381-391. https://doi.org/10.1016/S00225371(66)80048-8

Tversky, A., and Kahneman, D. 1973. 'Availability: A heuristic for judging frequency and probability', Cognitive Psychology, 5: 207-232. https://doi.org/10.1016/0010-0285(73)90033-9

Von Nitzsch, R., and Weber, M. 1993. 'The effect of attribute ranges on weights in multiattribute utility measurements', Management Science, 39: 937-943. https://doi.org/10.1287/mnsc.39.8.937 